\title{
Details of stress directions in the Alaska subduction zone from fault plane solutions
}

\author{
Zhong Lu, Max Wyss, and Hans Pulpan \\ Geophysical Institute, University of Alaska, Fairbanks
}

\begin{abstract}
We used the cumulative misfit method to divide a data set with heterogeneous stress orientations into subsets with homogeneous stress directions. We propose that slope changes of the cumulative misfit as a function of earthquake number pinpoint the boundaries of homogeneous stresses. Using a synthetic data set of 50 fault plane solutions, composed of two halves corresponding to two incompatible stress tensors, we tested the validity and efficacy of the cumulative misfit method. Our acceptance criteria for results of stress tensor inversions are (1) the directions must be well constrained, that is, the $95 \%$ confidence regions of the greatest and least principal stresses do not overlap and (2) there must be evidence for homogeneity in the sample, that is, the average misfit of the inversion is less than $6^{\circ}$. We estimated stress directions in the Alaska Wadati-Benioff Zone (WBZ) using 470 fault plane solutions, which we determined for earthquakes with $M_{L} \sim 3$, and 67 published fault plane solutions for earthquakes with $M_{s} \sim 5$. We succeeded in subdividing the data set of the small and large earthquakes into 25 and 3 subsets, with the average misfit ranging from $3.2^{\circ}$ to $5.5^{\circ}$. The average misfits of the subsets we accept as satisfying the assumption of homogeneity are smaller than the average misfit of the overall data set $\left(F \sim 10^{\circ}\right)$ by factors of 2 to 3. We estimated the stress fields at two scales along the Alaska WBZ. The stress directions measured by the large earthquakes $\left(M_{s} \sim 5\right)$ were homogeneous over large volumes, with extension downdip and the direction of greatest compression along strike. This unusual orientation of the greatest principal stress is attributed to the bend of the slab under central Alaska, which generates compressive stresses along strike. The stress orientations revealed by small earthquakes, in contrast, exhibited a great deal of heterogeneity as a function of space, although their general trend confirms the overall stress directions obtained from the large events. We propose that the ratio of the dimensions of the stress field sensed by earthquakes to the rupture dimensions is about 20 to 50 . The estimated stress directions of the crustal earthquakes corresponded to the following mechanisms: (1) strike-slip faulting with the greatest principal stress oriented N-S near Fairbanks and (2) thrusting with the greatest principal stress oriented NW-SE near Mount McKinley.
\end{abstract}

\section{Introduction}

In this paper, we deal with three separate but related subjects: we test the validity of the cumulative misfit method to identify boundaries between different stress regimes, we estimate details of the stress directions in a subduction zone, and we compare stress directions estimated based on small and large earthquakes. We show in detail for a synthetic data set with heterogeneous stress directions how to select homogeneous subsets, thereby indicating the validity of the cumulative misfit method [Wyss and $L u, 1995 ; \mathrm{Lu}$ and Wyss,

Copyright 1997 by the American Geophysical Union.

Paper number 96JB03666.

0148-0227/97/96JB-03666\$09.00
1996]. This systematic subdivision into volumes of homogeneous stress orientations permits the investigation of the stress distribution in the Alaska Wadati-Benioff Zone (WBZ) at much smaller scales than previously possible.

1. We test the validity and efficacy of the cumulative misfit method proposed by Wyss and $L u$ [1995] and $L u$ and Wyss [1996] and propose criteria for accepting the stress tensor orientation estimated from inversion of fault plane solutions. The purpose of the cumulative misfit method is to define the extent of volumes with homogeneous stress directions based on the misfit of individual fault plane solutions, calculated with respect to several assumed stress tensors. Using this method, Wyss and $L u$ [1995] identified the same stress boundaries as those proposed by Jones [1988] from tectonic considerations along the southern San Andreas fault. 
Lu and Wyss [1996] successfully found the locations of stress segmentation boundaries along the Aleutian arc based on this technique. However, the cumulative misfit method has not been tested quantitatively. In this paper, therefore, we will use synthetic data to test the method. We will also propose criteria for accepting the stress tensors estimated from the inversion of fault plane solutions.

2. We estimate the detailed stress directions along the Alaska WBZ on scales of a few tens of kilometers, using the cumulative misfit method to subdivide the zone into sections with homogeneous stress directions. Directions of stress in subduction zones were essentially settled during the discoveries related to plate tectonics. In several papers it was shown that the fault planes of intermediate and deep earthquakes were not parallel to the WBZ and that consistently either the $P$ or the $T$ axis (compressive and tensional bisectrices, respectively, of focal mechanisms) are oriented downdip [e.g., Isacks and Molnar, 1971; Isacks et al., 1968; Bhattacharya and Biswas, 1979; House and Jacob, 1983]. From this it was concluded that the subducting slabs act as stress guides, which are either in downdip compression or tension, depending on their length and history. Although we do not doubt that this view of the stress field in subducting slabs is essentially correct, there must be substantial deviations from this basic condition in bends of slabs (along strike as well as downdip), as expected from detailed slab models [e.g., Creager and Boyd, 1991; Creager et al., 1995]. In addition, perturbations of the stress directions may also exist in relatively straight slab segments as suggested by the orientations of $P$ and $T$ axes of small earthquakes or composite solutions [e.g., Reyners and Coles, 1982; Matsuzawa et al., 1986; Smith et al., 1993; Wiens et al., 1993; Comte and Suarez, 1994; Iguchi et al., 1995]. In the WBZ below Cook Inlet, for example, the $T$ axes of composite focal mechanisms tend to point downdip, increasing their dip as the dip of the WBZ increases with depth [Kissling and Lahr, 1991; Lahr et al., 1993, 1994]. Some detailed analyses of subducting slabs, which have concentrated on mapping the $P$ and $T$ axes [e.g., Lahr et al., 1993, 1994; Iguchi et al., 1995], found variations in these parameters. However, it is not necessarily correct to interpret the $P$ and $T$ axes as the directions of the greatest and least principal stress because earthquakes could occur along faults that are preexisting planes of weakness [McKenzie, 1969]. In a preliminary study, Li et al. [1995] found differences in stress directions within volumes defined on the basis of geographical distribution of hypocenters in the Alaska WBZ. In this paper we investigate the details of the stress directions in the Alaska WBZ on scales of a few tens of kilometers. We use the focal mechanisms of earthquakes, instead of $P$ and $T$ axes, to resolve stress directions in the slab. We apply the cumulative method [Wyss and $L u, 1995 ; L u$ and Wyss, 1996] to define the volumes of homogeneous stress directions.

3. We compare the stress inversion results from small $\left(M_{L} \sim 3\right)$ and large $\left(M_{s} \sim 5\right)$ earthquakes in the same area and then investigate the scale dependency of a stress field. The scale at which stress directions can be estimated from fault plane solutions has not been discussed in the literature. Geologists are, however, aware of this problem. For example, Rebai et al. [1992, Figure 3] show how large and small faults may perturb the regional stress field and lead to locally varying stress regimes. In the meantime, a basic assumption for the inversion of fault plane solutions to estimate stress direction is that all earthquakes occur in response to a single stress tensor. Thus, if we mix fault plane solutions from volumes with different stress directions, our results will be invalid, but we may not recognize this condition [e.g., Michael, 1987]. Therefore it may not be advisable to mix small and large earthquakes in data sets to be inverted, even if they are located in the same area. Inverting fault plane solutions for stress directions in Sicily, Caccamo et al. [1997] noticed that large and small earthquakes in the same area do not always conform to the same stress tensor.

One of the key questions of the scale that arises in seismology is: What is the relationship between the rupture dimensions of earthquakes and the dimensions of the stress field that generate these earthquakes? We suspect that it is not likely that ruptures along substantial segments of large faults reflect local perturbations of the stress field. Instead we expect them to respond to the large-scale overall stress field. We define "large earthquakes" as $M_{s} \sim 5$, having rupture dimensions of about $10 \mathrm{~km}$. The small earthquakes $\left(M_{L} \sim 3\right)$ we describe in this investigation have source dimensions of a few hundred meters. These small earthquakes could occur in response to the overall stress field just as large earthquakes do, if they occur in volumes that are not perturbed. However, because of their small dimensions they can also reflect local perturbations of the stress field. If we have enough small earthquakes in such a volume, we may then derive the locally perturbed stress directions by inversion. Because of the limitation of the number of the earthquake focal mechanisms we have, we could only subdivide the data set into two categories with $M_{s} \sim 5$ and $M_{L} \sim 3$, respectively. In this paper, we invert the fault plane solutions of large and small earthquakes in Alaska separately. This separation has the advantage of examining the same area at two different length scales. We subdivide the data set as a function of space, with the aim of finding homogeneous sets that define the stress directions in relatively small volumes and ensuring that the assumption of homogeneity is fulfilled.

\section{Stress Tensor Inversion and the Cumulative Misfit Method}

\section{Stress Tensor Inversion Method}

To determine stress directions from fault plane solutions, we use the focal mechanism stress inversion (FMSI) computer programs which were developed to 
find the orientation of a best fitting principal stress tensor to a group of earthquakes by grid search over a range of possible models [Gephart and Forsyth, 1984; Gephart, 1990] under the assumption that the slip on the fault plane occurs in the direction of the resolved shear stress [Bott, 1959; McKenzie, 1969] and that the stress orientation is homogeneous in the study area [e.g., Angelier, 1979; Michael, 1984; Yin and Ranalli, 1993]. The misfit for each earthquake is defined as the smallest rotation angle about an axis of any orientation that would bring the direction and sense of slip, associated with either of the two observed nodal planes, into agreement with the direction and the sense of slip predicted by the stress model [Gephart and Forsyth, 1984; Gephart, 1990]. The best fitting stress tensor is found by minimizing the average of the individual misfits $(F)$. The parameters of the stress tensor obtained by the method are the azimuths and plunges of the three principal stresses and a measure of stress magnitude, $R$, indicating the magnitude ratio of the intermediate principal stress relative to the two extreme ones $\left(R=\left(\sigma_{1}-\sigma_{2}\right) /\left(\sigma_{1}-\sigma_{3}\right)\right.$, where $\sigma_{1}, \sigma_{2}$, and $\sigma_{3}$ are the greatest, intermediate, and least principal stresses, respectively).

\section{Criteria for Successful Inversions}

We propose that the average misfit $F$ is made up of two components: (1) a contribution from errors in the fault plane solutions and (2) heterogeneity in the stress field that caused the earthquakes in the data set. Thus we subdivide the data set until we find the smallest possible average misfit $F$ in any subset of the data containing the minimum number of events we require to attempt an estimate of stress directions (usually $N>15$ ). Assuming that the quality of fault plane solutions does not vary significantly as a function of space, we surmise that every inversion will result in an $F$ that contains approximately $F_{\min }$ due to errors in fault plane solutions, and the rest, $F_{\text {tect }}$, will be due to heterogeneity of the tectonic stress field. Hence we can write

$$
F=F_{\min }+F_{t e c t}
$$

If $F_{t e c t}$ is smaller than a threshold, we may term the data set satisfactorily homogeneous; if it is larger, we will reject the inversion result as one contaminated substantially by heterogeneity. We estimate $F_{\min }$ by selecting from our large data set of several hundred earthquakes a subset for which $F_{\text {tect }}$ may approach zero or be negligibly small. We will assume that the smallest $F$ we obtain for any subset, using a number of events large enough to obtain a stable solution (usually $\mathrm{N}>$ 15 ), will be an indication of $F_{m i n}$, provided that this value is less than $6^{\circ}$ [Wyss et al., 1992; Gillard et al., 1996]. This requirement is based on the observation that synthetic data sets with errors of $15^{\circ}$ (average of the uncertainties in the strike, dip, and rake) lead to $F \leq 6^{\circ}$ [Wyss et al., 1992; Gillard et al., 1996] which is reasonable for our data set, since the average values are less than $15^{\circ}$ (see Data subsection under Stress Di- rections Along the Alaska WBZ section). Therefore, the average misfit is the first criterion to estimate the degree of heterogeneity in a sample.

The limit of the $95 \%$ confidence regions of the orientation of the principal stress axes is the second criterion for judging the quality of the inversion results. A stress tensor is accepted if the $95 \%$ confidence regions of the greatest and least principal components of the tensor are well constrained, i.e., do not overlap. In this paper, we reject the stress inversion result if the $95 \%$ confidence region of the greatest or the least principal stress exceeds $30 \%$ of the hemisphere. The $95 \%$ confidence regions are also used to judge the difference of two stress tensors. If the corresponding $95 \%$ confidence regions of two stress tensors do not overlap, we term the two stress tensors as significantly different at the $95 \%$ level. We use the terms "meaningful" and "useful" to mean that inversion results do not violate our acceptance criteria.

\section{Cumulative Misfit Method}

The cumulative misfit method [Wyss and $L u, 1995$; $L u$ and Wyss, 1996] is used as a tool to find volumes containing homogeneous data sets. In this method we use a test stress tensor to calculate the misfit for every earthquake in the data set. We plot the cumulative misfit of sequential events as a function of distance along strike (or depth or time if these parameters are of interest) expecting to see changes in slope of this curve (i.e., changes in average misfit) wherever the orientation of the stress tensor changes. For the segment of the data set for which the test tensor is the best solution, the misfits will be small (i.e., the slope of the cumulative curve will be low), but for neighboring segments for which the test tensor is not correct, the misfits are likely to be larger, leading to a steeper slope of the curve [Wyss and $L u, 1995 ; L u$ and Wyss, 1996]. The contrast between slopes in segments with different stress tensors depends in a nonlinear way on the choice of the test tensor. In particular, we may not be certain that we have found all existing boundaries between realms of different stress directions. However, where we find a statistically significant contrast between average misfits, we have successfully defined a boundary, if we can also show that $F$ in separate inversions of the subsets is significantly lower than $F$ of the joint data. The statistical significance of the difference between segments is measured by the standard deviate $\mathrm{z}$ test [Wyss and $L u$, 1995; $L u$ and Wyss, 1996]. We use several test tensors to define homogeneous subsets and use the average of estimates of the slope changes of the cumulative misfit curves for possible stress segmentation boundary locations.

\section{Test of Cumulative Misfit Method}

To demonstrate the validity of the cumulative misfit method for detecting difference in stress orientations, we applied it to a synthetic data set containing two incompatible subsets. We created two data sets with 
Table 1. Stress Tensor Results

\begin{tabular}{|c|c|c|c|c|c|c|c|c|c|c|c|c|}
\hline \multirow{2}{*}{ Set } & \multirow{2}{*}{$\mathbf{N}$} & \multirow{2}{*}{$\begin{array}{c}\text { F, } \\
\text { deg }\end{array}$} & \multirow{2}{*}{ Depth, km } & \multirow{2}{*}{$M$} & \multicolumn{2}{|c|}{$\sigma_{1}$} & \multicolumn{2}{|c|}{$\sigma_{2}$} & \multicolumn{2}{|c|}{$\sigma_{3}$} & \multirow{2}{*}{$R$} & \multirow{2}{*}{ I } \\
\hline & & & & & PL & $\mathbf{A Z}$ & PL & $A Z$ & PL & $\mathbf{A Z}$ & & \\
\hline so & 67 & 10.2 & $<40$ & -3 & & & & & & & & \\
\hline S1 & 403 & 12.7 & $40-140$ & -3 & & & & & & & & \\
\hline $\mathbf{L}$ & 67 & 8.5 & $0-140$ & -5 & 1 & 222 & 75 & 128 & 15 & 312 & 0.2 & \\
\hline $\mathrm{La}$ & 15 & 3.3 & $0-40$ & -5 & 2 & 207 & 87 & 78 & 2 & 297 & 0.6 & 7 \\
\hline Lb & 33 & 4.0 & $55-140$ & $\sim 5$ & 2 & 191 & 55 & 98 & 35 & 282 & 0.6 & 7 \\
\hline Lc & 19 & 5.0 & $55-140$ & -5 & 2 & 78 & 30 & 169 & 60 & 343 & 0.7 & 7 \\
\hline Ld & 48 & 6.9 & $0-140$ & -5 & 2 & 191 & 55 & 98 & 35 & 282 & 0.7 & \\
\hline 1 & 32 & 7.5 & $<40$ & -3 & 12 & 147 & 9 & 55 & 75 & 290 & 0.3 & \\
\hline IW & 18 & 3.8 & $<40$ & -3 & 7 & 147 & 9 & 56 & 79 & 273 & 0.5 & 6 \\
\hline IE & 14 & 5.8 & $<40$ & -3 & 22 & 151 & 68 & 328 & 1 & 61 & 0.4 & 13 \\
\hline 2 & 35 & 8.7 & $<40$ & $\sim 3$ & 16 & 350 & 43 & 96 & 42 & 245 & 0.6 & \\
\hline $2 \mathrm{~N}$ & 16 & 3.8 & $<40$ & -3 & 28 & 9 & 43 & 128 & 35 & 258 & 0.5 & 6 \\
\hline $2 S$ & 19 & 8.9 & $<40$ & -3 & 26 & 144 & 1 & 54 & 64 & 321 & 0.3 & 13 \\
\hline 3 & 19 & 3.3 & $<40$ & -3 & 72 & 218 & 17 & 21 & 5 & 112 & 0.4 & II \\
\hline 4 & 39 & 8.1 & $40-50$ & -3 & 43 & 187 & 44 & 33 & 13 & 290 & 0.4 & \\
\hline $4 a$ & 23 & 4.3 & $40-50$ & -3 & 43 & 184 & 43 & 32 & 14 & 288 & 0.4 & II \\
\hline $4 b$ & 16 & 6.1 & $40-50$ & -3 & 45 & 248 & 42 & 41 & 14 & 144 & 0.5 & 13 \\
\hline 5 & 48 & 10.0 & $50-60$ & -3 & 12 & 21 & 72 & 150 & 14 & 288 & 0.6 & \\
\hline $5 a$ & 17 & 3.2 & $50-60$ & -3 & 2 & 152 & 88 & 284 & 2 & 62 & 0.6 & 12 \\
\hline $5 b$ & 10 & 5.4 & $50-60$ & -3 & 80 & 93 & 0 & 2 & 10 & 272 & 0.8 & 13 \\
\hline $5 c$ & 19 & 4.8 & $50-60$ & -3 & 72 & 42 & 17 & 211 & 3 & 302 & 0.5 & 12 \\
\hline 6 & 67 & 10.2 & $60-75$ & -3 & 52 & 115 & 6 & 18 & 38 & 283 & 0.5 & \\
\hline $6 a$ & 12 & 4.0 & $60-75$ & -3 & 11 & 150 & 79 & 324 & 1 & 60 & 0.6 & 10 \\
\hline $6 \mathrm{~b}$ & 12 & 3.6 & $60-75$ & -3 & 12 & 7 & 73 & 140 & 12 & 274 & 0.6 & 10 \\
\hline $6 c$ & 18 & 3.7 & $60-75$ & -3 & 30 & 67 & 17 & 167 & 55 & 282 & 0.7 & 10 \\
\hline $6 d$ & 18 & 4.9 & $60-75$ & -3 & 62 & 162 & 8 & 268 & 27 & 3 & 0.3 & 10 \\
\hline 7 & 48 & 10.2 & $75-90$ & $\sim 3$ & 3 & 187 & 60 & 92 & 30 & 279 & 0.4 & \\
\hline $7 a$ & 7 & 1.6 & $75-90$ & -3 & 48 & 196 & 40 & 355 & 11 & 94 & 0.6 & 11 \\
\hline $7 b$ & 15 & 5.1 & $75-90$ & -3 & 55 & 51 & 10 & 155 & 34 & 252 & 0.5 & 11 \\
\hline $7 c$ & 13 & 7.3 & $75-90$ & -3 & 31 & 229 & 42 & 105 & 32 & 341 & 0.4 & 13 \\
\hline $7 d$ & 12 & 1.9 & $75-90$ & -3 & 3 & 187 & 60 & 91 & 30 & 279 & 0.3 & 11 \\
\hline 8 & 83 & 11.1 & $90-120$ & $\sim 3$ & 15 & 24 & 55 & 136 & 31 & 284 & 0.5 & \\
\hline $8 \mathbf{a}$ & 15 & 3.4 & $90-120$ & -3 & 18 & 213 & 22 & 116 & 61 & 339 & 0.6 & 12 \\
\hline $8 b$ & 16 & 3.2 & $90-120$ & -3 & 21 & 4 & 4 & 272 & 69 & 171 & 0.6 & 12 \\
\hline $8 c$ & 16 & 4.7 & $90-120$ & -3 & 27 & 53 & 45 & 174 & 33 & 304 & 0.6 & 12 \\
\hline
\end{tabular}


Table 1. (continued)

\begin{tabular}{|c|c|c|c|c|c|c|c|c|c|c|c|c|}
\hline \multirow{2}{*}{ Set } & \multirow{2}{*}{$\mathbf{N}$} & \multirow{2}{*}{$\begin{array}{c}\text { F, } \\
\text { deg }\end{array}$} & \multirow{2}{*}{ Depth, km } & \multirow{2}{*}{$M$} & \multicolumn{2}{|c|}{$\sigma_{1}$} & \multicolumn{2}{|c|}{$\sigma_{2}$} & \multicolumn{2}{|c|}{$\sigma_{3}$} & \multirow{2}{*}{$\boldsymbol{R}$} & \multirow{2}{*}{ I } \\
\hline & & & & & PL & $\mathbf{A Z}$ & $\mathbf{P L}$ & $\mathbf{A Z}$ & PL & $\mathbf{A Z}$ & & \\
\hline $8 d$ & 14 & 5.0 & $90-120$ & -3 & 6 & 216 & 50 & 119 & 39 & 312 & 0.5 & 12 \\
\hline 9 & 71 & 10.4 & $120-140$ & -3 & 2 & 36 & 46 & 128 & 44 & 305 & 0.5 & \\
\hline $9 a$ & 21 & 3.8 & $120-140$ & -3 & 4 & 205 & 49 & 110 & 41 & 298 & 0.5 & 10 \\
\hline $9 b$ & 21 & 4.0 & $120-140$ & -3 & 39 & 167 & 19 & 60 & 44 & 310 & 0.8 & 10 \\
\hline $9 \mathrm{c}$ & 19 & 5.5 & $120-140$ & -3 & 13 & 33 & 46 & 137 & 41 & 292 & 0.6 & 10 \\
\hline
\end{tabular}

$N$, number of events; $F$, average misfit angle; $M$, magnitude; $\sigma_{1}$, greatest principal stress; $\sigma_{2}$, intermediate principal stress; $\sigma_{3}$, least principal stress; $A Z$, azimuth; PL, plunge; $R$, magnitude ratio of principal stresses (see text); $I$. indicating figure where region of data set is defined and the $95 \%$ confidence map is shown.

25 events in each group. We first randomly picked 25 events from our subset 8 in Table 1 and 25 events from subsets 1, 2, and 3 in Table 1 and adjusted them in such a way that the slip vector on one of the nodal planes coincides with the predicted slip direction associated with a presumed stress tensor. The distributions of $P$ and $T$ axes of these two sets of events are shown in Figures 1a and 1g. Inversion for stress directions of the first set (earthquakes 1 to 25 in Figure 1) yields $\sigma_{1}=145^{\circ} / 10^{\circ}$ (azimuth/plunge), $\sigma_{2}=245^{\circ} / 44^{\circ}, \sigma_{3}=$ $45^{\circ} / 44^{\circ}, R=0.5$, and $F=0.8^{\circ}$ (Figure $1 \mathrm{~b}$ ), which is within $5^{\circ}$ of the values of the presumed stress tensor. Inverting the second set of 25 events (earthquakes 26 to 50 in Figure 1, with $P$ and $T$ axes shown in Figure $1 \mathrm{~g}$ ) for stress direction results in $\sigma_{1}=215^{\circ} / 60^{\circ}$, $\sigma_{2}=18^{\circ} / 29^{\circ}, \sigma_{3}=112^{\circ} / 7^{\circ}, R=0.5$, and $F=0.7^{\circ}$ (Figure $1 \mathrm{~h}$ ). We then performed stress inversions in a moving window, that is, the earthquakes falling within the window are inverted and the average misfit is determined; then the window is advanced by one earthquake along the abscissa. This method is based on the idea that average misfits will become bigger if the segmentation boundary falls within the window. Therefore the segmentation boundaries should be near the peaks of curves of average misfit versus window position. Figure 1 shows the average misfit as a function of position of the moving window for several different window lengths, i.e., $10,13,15,17,20,22,25,28,30,33$, and 50 earthquakes. We find that inversions of samples confined to one of the two homogeneous data sets always result in $F<1.0^{\circ}$. Misfits of $F>1.0^{\circ}$ indicate that the earthquakes are not confined to one of the two homogeneous data sets. As long as the moving window includes the segmentation boundary (between earthquakes 25 and 26), the inversion will yield a significant increase of the misfit. The horizontal line in Figure 1 separates valid results (below the line) from inversion results that are meaningless, as the data come from two stress regimes. We interpret $F \sim 1.0^{\circ}$ as $F_{\min }$ in this case and use it as a guide for judging inversion results in this test. Note that there are no errors due to fault plane uncertainties in the synthetic data set; so $F_{\min }$ is smaller than what one would expect in real data sets.

Figure 1 also demonstrates the second criterion used for judging inversion results, that is, that the $95 \%$ confidence regions of the greatest and least principal stress directions are well constrained. Inverting 10 earthquakes from each data set (i.e., earthquakes 1 to 10 and 41 to 50 ) yields the same stress directions as those from 25 events; however, the $95 \%$ confidence regions for $\sigma_{1}$ and $\sigma_{3}$ are larger (Figures $1 \mathrm{~d}$ and $1 \mathrm{j}$ ). Because the misfits of the inversions for $N=10$ events are around $1.0^{\circ}$ and the $95 \%$ confidence regions for $\sigma_{1}$ and $\sigma_{3}$ are well constrained, we interpret the inversion results as acceptable. Inversion for stress directions for five events from each data set separately (i.e., earthquakes 1 to 5 and 46 to 50 ) results in $F \sim 1.0^{\circ}$ also. The distributions of $P$ and $T$ axes for this case are shown in Figures $1 \mathrm{e}$ and $1 \mathrm{k}$, respectively. However, $95 \%$ confidence regions for $\sigma_{1}$ and $\sigma_{3}$ overlap, and hence we reject the results (Figures 1f and 11). The inversion results for the five event sets would be misinterpreted if we neglected the second criterion for judging the inversion.

In order to help show how the cumulative misfit method [Wyss and Lu, 1995; Lu and Wyss, 1996] could be used to pick up the stress segmentation boundary between earthquakes 25 and 26 , we use seven stress tensors as reference models, calculate the misfit of individual events with respect to each reference stress tensor, and then plot the cumulative misfit as a function of earthquake number (Figure 2). The seven reference stress models are shown at the upper left corner of Figure 2. Based on this method, the changes of slopes in the cumulative misfit curves resulting from the application of several stress tensors are interpreted as the segmentation boundaries [Wyss and $L u, 1995 ; L u$ and Wyss, 1996]. Six out of seven cumulative misfit plots clearly show the stress segmentation boundary between earth- 


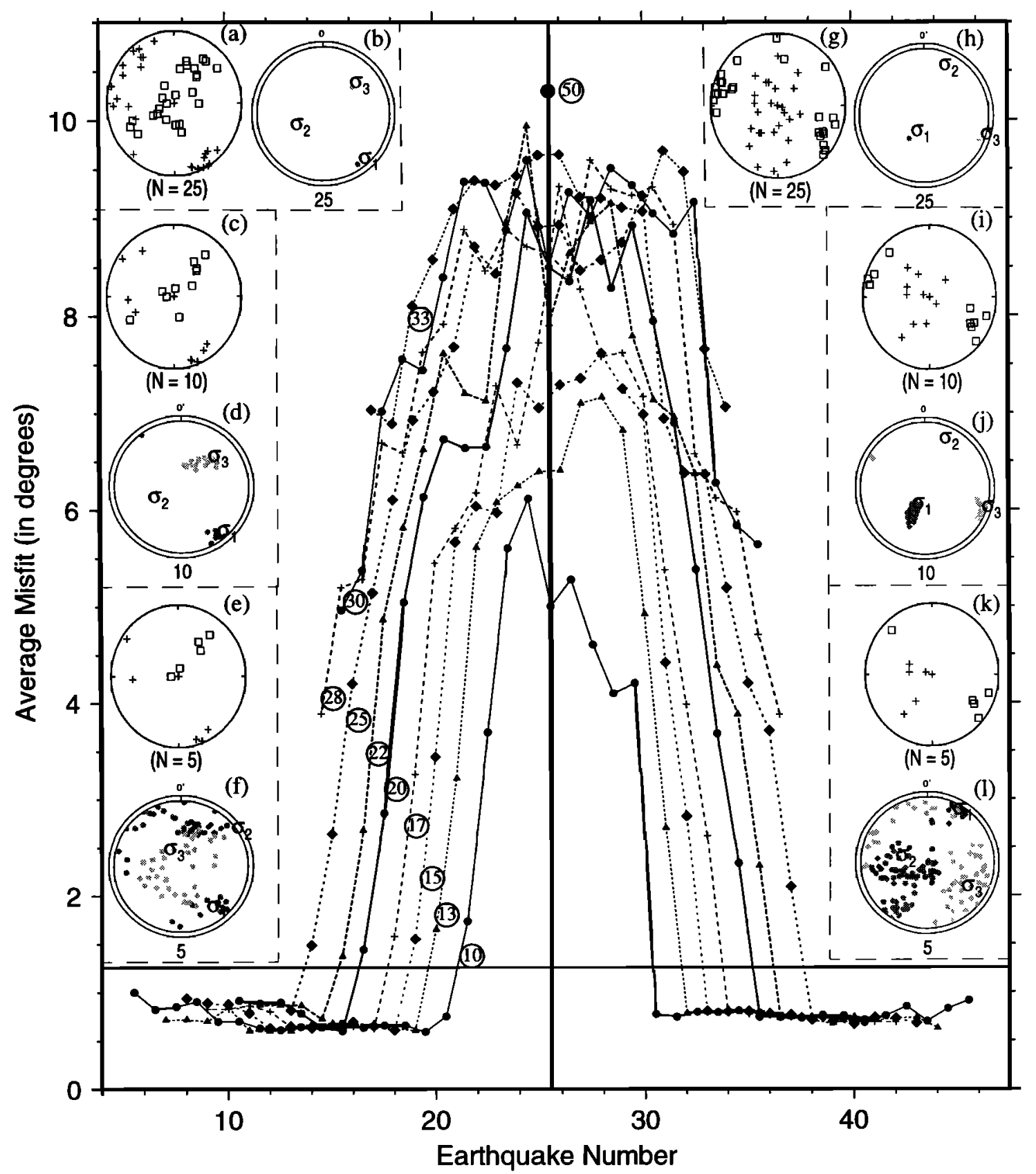

Figure 1. Average misfit for inversions for stress directions as a function of position of the moving windows for several window lengths, $10,13,15,17,20,22,25,28,30,33$, and 50 . The data come from two synthetic sets with different stress regimes. The vertical line between earthquakes 25 and 26 marks the boundary of change in stress directions. Figures 1b, 1d, and 1f are stereographic projections of stress direction estimates based on inversions of fault plane solutions from the first set (earthquakes 1 to 25 ), and Figures $1 \mathrm{~h}, 1 \mathrm{j}$, and $1 \mathrm{l}$ are those from the second set (earthquakes 26 to 50 ). The $95 \%$ confidence regions for the greatest and least principal stresses are shown by heavy and light shading, respectively. The orientation of $P$ (pluses) and $T$ (squares) axes of the focal mechanisms used in the inversions are shown in Figures 1a, 1c, 1e, 1g, 1i, and 1k.

quakes 25 and 26 . The stress boundary does not show up if the test tensor is close to that best fitting the over all data set of $\mathrm{N}=50$ (curve $d$ in Figure 2). Thus we conclude that the method proposed by Wyss and $L u$ [1995] and $L u$ and Wyss [1996] is able to identify at least in some cases the stress segmentation boundaries, if we use several reference stress tensors and to use the av- erage estimates for stress segmentation locations. The ratio of computation time for preforming stress inversions as in the moving window analysis (Figure 1) and cumulative misfit analysis (Figure 2) is 100:1, approximately. This shows that the cumulative misfit method is not only effective, but also time saving.

The size of $F$ may depend inversely on $\mathrm{N}$, the num- 


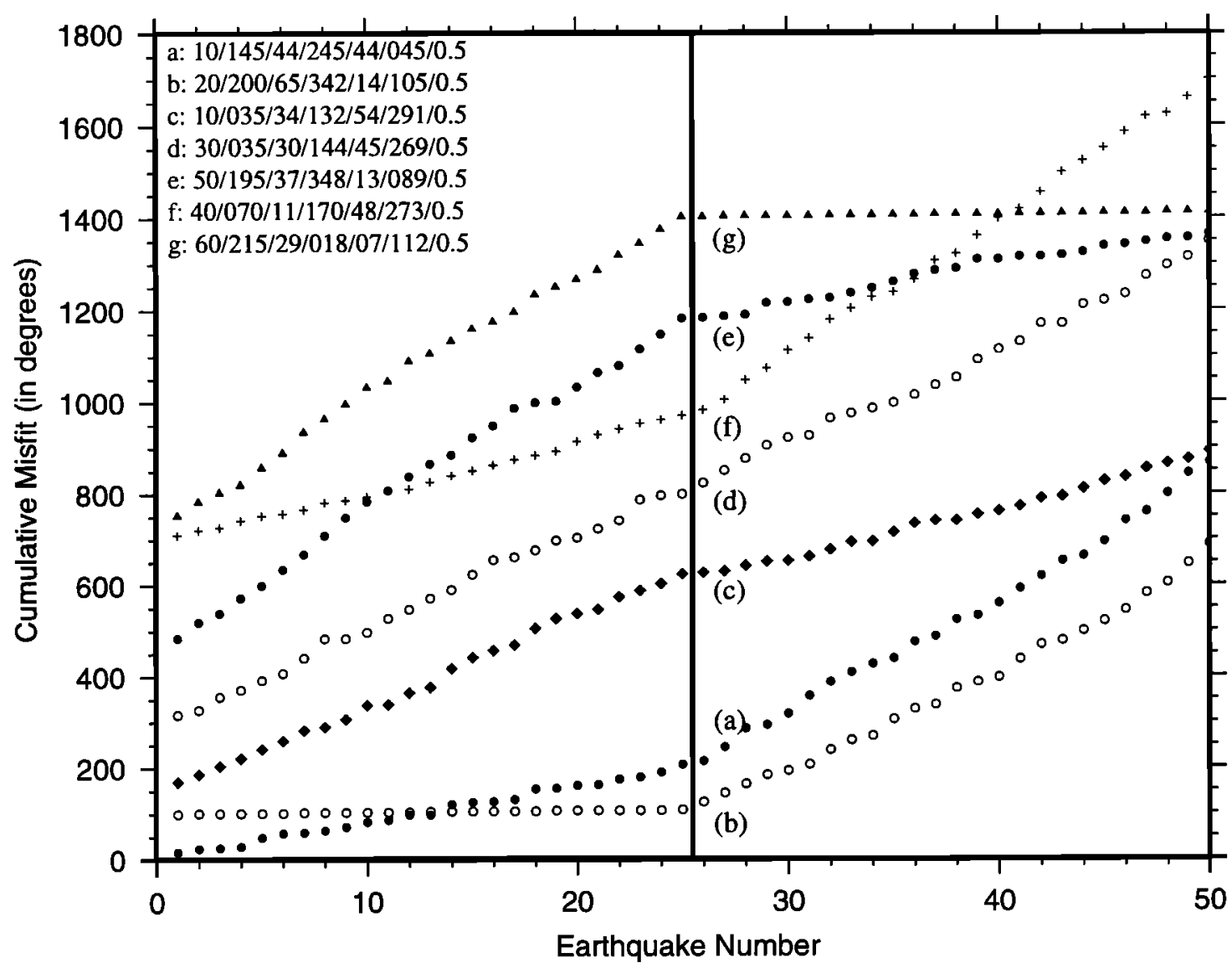

Figure 2. Cumulative misfit as a function of earthquake number for seven reference stress tensors. All but the lowest curve have been shifted upward for clarity. The earthquakes are the same as those in Figure 1. The reference stress tensors used to calculate the misfit of individual earthquakes are shown in the upper left corner. These stress tensors are represented by plunge and azimuth of $\sigma_{1}, \sigma_{2}, \sigma_{3}$, and $R$ (see text).

ber of events in the inversion. If $F$ is a strong function of $\mathrm{N}$, we have to account for this effect in our criteria for accepting inversion results. To help show how the average misfit changes as a function of the number of earthquakes used in the inversion, we combine the two synthetic data sets (Figure 1) into a single set. We randomly select a number of earthquakes from this single data set and invert for stress directions, obtaining an average misfit. Figure 3 shows the average misfit and its standard deviation as a function of $\mathrm{N}$ selected randomly from a total of 50 events. The average misfit is reduced about $1.5^{\circ}$ (from $10.2^{\circ}$ to $8.7^{\circ}$ ) if we reduce the earthquake number from 50 to 25 and about $2.3^{\circ}$ (from $8.7^{\circ}$ to $6.4^{\circ}$ ) if we reduce the earthquake number from 25 to 12 (Figure 3). Thus the average misfit can be reduced about $15 \%$ to $25 \%$ in this heterogeneous data set if the number of earthquakes is cut in half.

The way to significantly reduce the misfit is by identifying correctly the segmentation boundaries and then inverting separately the events within the volumes identified by the boundaries. For comparison, we plot $F$ of the inversion results, which are shown in Figure 1 and do not contain the segmentation boundary, in the lower part of Figure 3. In these cases, $F$ is not a function of $\mathrm{N}$, and the average misfit is reduced by almost an order of magnitude compared with the worst case of inversion result for $\mathrm{N}=50$, the heterogeneous full data set. This demonstrates that by inverting earthquakes from

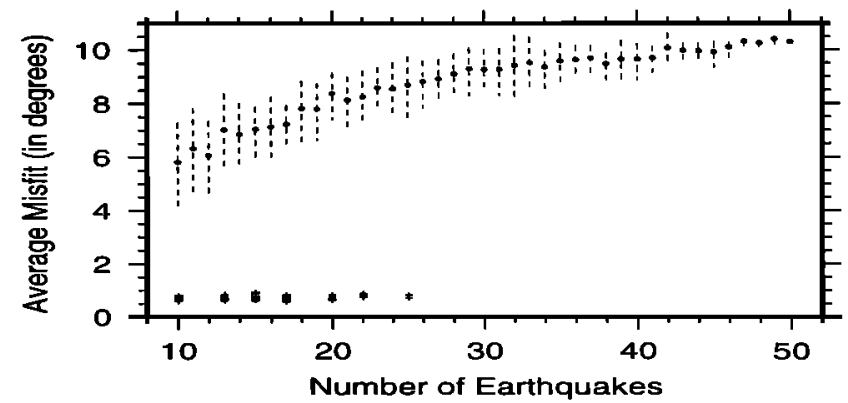

Figure 3. Average misfit (circles) and its standard deviation (dashed lines) as a function of the number of earthquakes. The data sets were selected randomly from 50 events which come from two stress regimes (Figures 1 and 2). The average misfits resulting from inversions of earthquakes from a single stress regime in Figure 1 are redrawn by pluses at the bottom. 


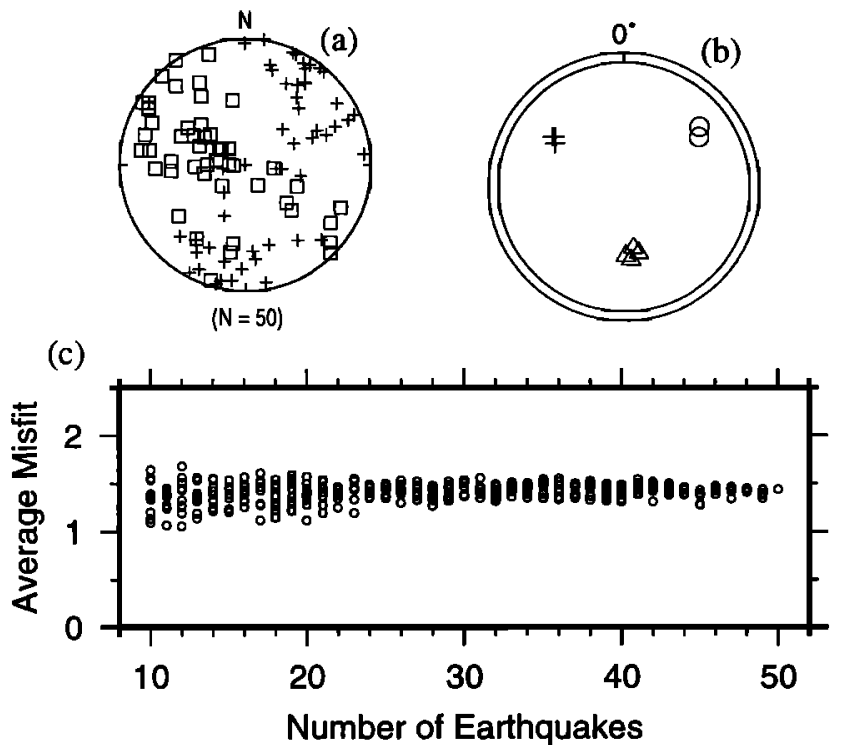

Figure 4. (c) Average misfits as a function of the number of earthquakes for data sets selected randomly from 50 events, which come from a single stress regime. (a) The orientation of $P$ (pluses) and $T$ (squares) axes of the 50 focal mechanisms plotted on a lower hemisphere, equal-area projection. (b) The greatest (circles), intermediate (triangles), and least (pluses) principal stress directions of the best fitting stress tensors from all the inversions.

a single stress regime, we could significantly reduce the misfit by a factor of 5 to 8 , approximately, compared with $F$ of the events selected randomly from the heterogeneous data set. Hence the reduction in misfit $F$ achieved by selection of the proper, i.e., homogeneous, subsets is far greater than that achieved by reducing the number of events with heterogeneous stress directions (Figure 3).

Next we created another set of 50 fault plane solutions compatible with a particular stress tensor. The $P$ and $T$ axes are shown in Figure 4a. The inversion using all 50 events yields $F \sim 1.5^{\circ}$. We then randomly selected different numbers of events from this single data set and inverted them for stress directions to obtain the average misfit. Figure $4 \mathrm{c}$ shows $F$ as a function of $\mathrm{N}$. The average misfit stays approximately the same regardless of the number of events used in the inversion. Figure $4 \mathrm{~b}$ shows the best fitting stress tensors from all the random inversions. The solutions of best fitting stress tensors are very stable. This test demonstrates that average misfits of subsets are not reduced significantly if the original data set consists of earthquakes that are homogeneous in stress direction. We conclude that in these cases, significantly reducing the average misfit could be achieved only if the existing stress segmentation boundaries were correctly identified.

Using synthetic data without uncertainties in the fault plane solutions, we found the stress segmentation boundary contained in the data. Using real data sets from the southern San Andreas fault, Wyss and Lu [1995] found the same stress segmentation boundaries as those identified by Jones [1988] based on tectonic considerations. Therefore we conclude that the cumulative misfit method is a valid tool to identify the stress segmentation boundaries based on the earthquake focal mechanism data. In the future, we plan to answer the questions whether the cumulative misfit works equally well for data sets with any errors in the fault plane solutions and for any mixture of faulting types.

\section{Discussion}

The cumulative misfit method for identifying changes in stress orientation gives no guarantee that all boundaries are found (curve $d$ in Figure 2). However, all boundaries found appear to be real. On the basis of tests on the heterogeneous synthetic data set, we propose that most of the test tensors find the location of change in stress direction. Thus we proceed as follows when searching for homogeneous subsets in a large but possibly heterogeneous set of fault plane solutions. We first calculate cumulative misfit curves based on one or several arbitrary test tensors. Then we select a subset of events that have approximately uniform misfits (constant slope) for inversion. If this results in $F \leq$ $6^{\circ}$ [Wyss et al., 1992; Gillard et al., 1996, Table 2] and confinement of the stress directions is adequate, then we have found a first meaningful solution that applies to a subset of the data. Then we use this first meaningful solution as a test tensor for the entire data set. The resulting cumulative misfit curve defines the extent of the data for which this test tensor is valid as the segment of the curve with the lowest slope. From this cumulative misfit curve and from any of the ones calculated before, we then select other subsets of the data for separate inversion, repeating the procedure to find homogeneous subsets as described above.

Estimates of stress directions by inversion of fault plane solutions might be meaningless if they are poorly constrained or derived from heterogeneous data sets. We use the $95 \%$ confidence limits calculated by using the method of Gephart and Forsyth [1984] as the criterion for judging the degree of constraint. For the homogeneity criterion we proposed the generic value of $F \leq$ $6^{\circ}$ for the average misfit [Wyss et al., 1992; Gillard et al., 1996]. We do not propose $F=6^{\circ}$ as a magic number that always separates homogeneous from heterogeneous sets. Rather we view it as an approximate limit, since the size of the two terms that make up $F$ in equation (1) is unknown. Because average misfits up to $6^{\circ}$ can in general be attributed to reasonably small errors in fault plane solutions $\left(15^{\circ}\right.$ ), solutions with $F \leq 6^{\circ}$ cannot be rejected. Therefore we accepted solutions with $F$ $\leq 6^{\circ}$ as satisfying the assumption of homogeneity and as meaningful, as long as the $\mathbf{9 5 \%}$ confidence regions for the greatest and least principal stresses do not overlap. Solutions with misfits in the range $6^{\circ}<F<7.5^{\circ}$ were 
accepted if the principal stresses are resolvable at the $95 \%$ confidence level, although they probably contain a moderate amount of heterogeneity. Inversions for stress directions resulting in $F \geq 7.5^{\circ}$ were rejected because they violate the assumption of homogeneity to a degree that is unacceptable. Beroza and Zoback [1993] and Zoback and Beroza [1993] in their studies of the stress orientation associated with the Loma Prieta earthquake and its aftershocks, accepted misfits of more than $10^{\circ}$. Our view is that values of this magnitude most likely reflect heterogeneity of stress directions in the data, considering that the fault plane solutions in the study area should be of high quality.

\section{Stress Directions Along the Alaska WBZ}

\section{Data}

The first part of the data set consists of 470 earthquakes with $M_{L}=3.0 \pm 0.5$ recorded by the Alaska Earthquake Information Center (Figure 5) and is com-

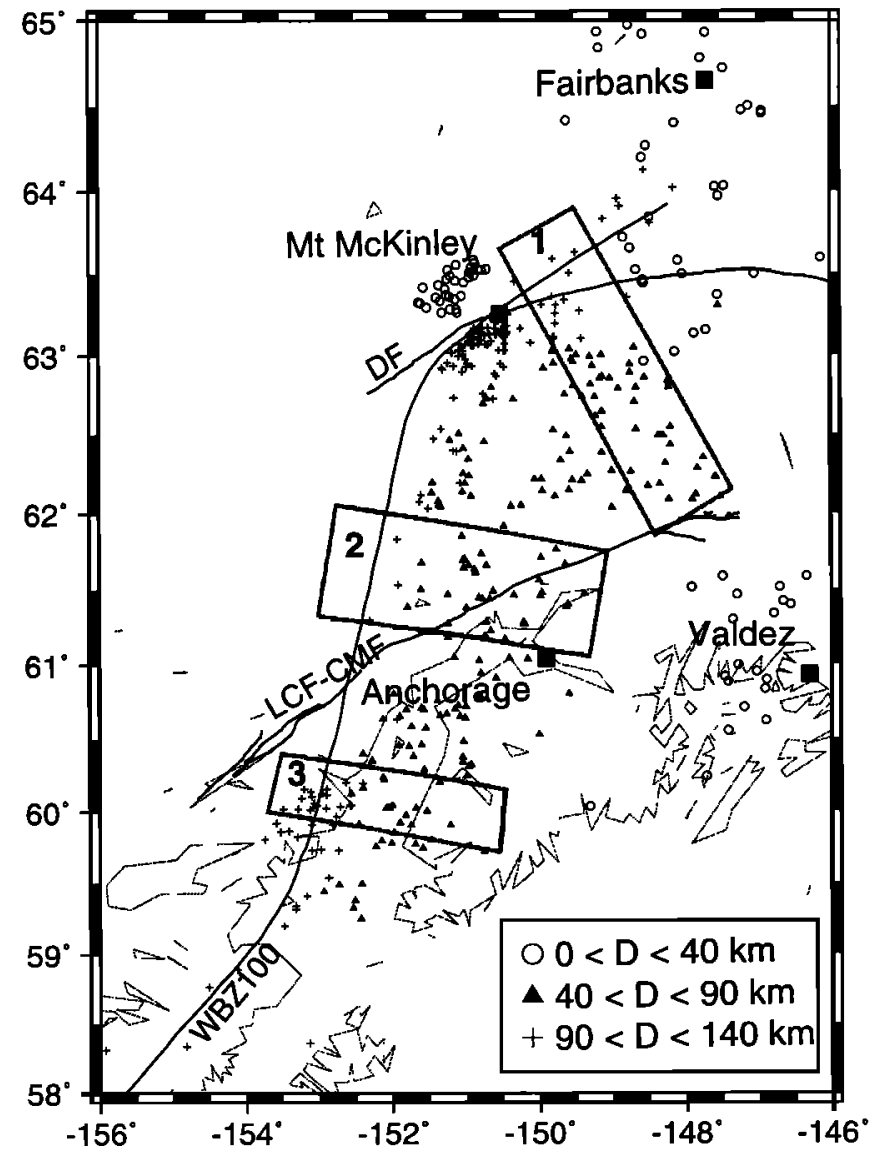

Figure 5. Epicenter map of 470 small earthquakes $\left(M_{L} \sim 3.0\right)$ with fault plane solutions in Alaska. The earthquakes in the areas enclosed by the three polygons are used to investigate the change of stress direction as a function of depth. Fault abbreviations: DF, Denali fault; LCF-CMF, Lake Clark fault and Castle Mountain fault; WBZ100, approximate surface projection of WBZ at $100 \mathrm{~km}$ depth.

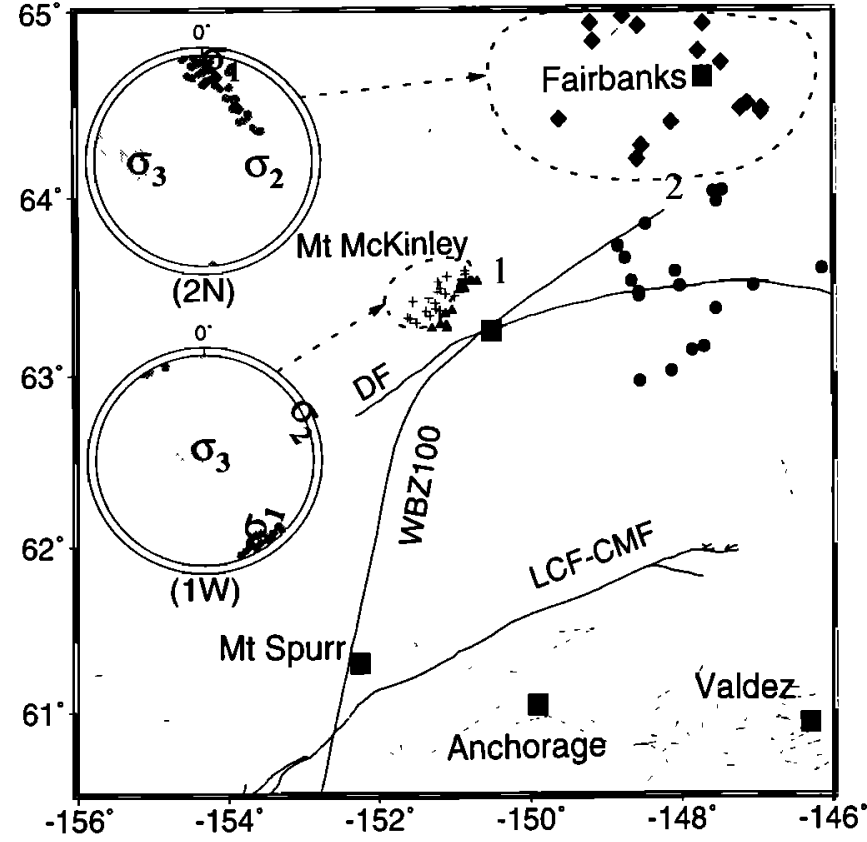

Figure 6. Epicenter map of small crustal earthquakes $\left(M_{L} \sim 3\right)$ with fault plane solutions in Alaska and stereographic projection of the best fitting principal stress directions for two homogeneous data sets: $1 \mathrm{~W}$ (crosses), west McKinley; 2N (diamonds) (Table1). The inversions using the data from the earthquakes marked by triangles and dots do not yield meaningful results (see text). The $95 \%$ confidence regions are defined by heavily and lightly shaded dots for the greatest and least principal stresses, respectively.

posed of two distinct classes of earthquakes: (1) crustal earthquakes in the overriding plate (North America Plate) and (2) WBZ earthquakes within the subducting part of the oceanic plate (Pacific Plate) landward of the trench. Among the 470 earthquakes, 67 are crustal events in the overriding plate. These crustal events $(D<40 \mathrm{~km})$ are distributed in two patches of the study area: the first is near $63.5^{\circ} \mathrm{N}, 151^{\circ} \mathrm{W}$; the second is spread widely within $63^{\circ}-65^{\circ} \mathrm{N}$ and $146.5^{\circ}-149.5^{\circ} \mathrm{W}$ (Figure 6). The 19 events in the area between Anchorage and Valdez with $\mathrm{D}<40 \mathrm{~km}$ (Figure 5) are located in the oceanic plate based on the detailed seismicity study of Page et al. [1989]. The WBZ earthquakes with 40 $<\mathrm{D}<90 \mathrm{~km}$ are distributed approximately evenly in the study area. For deep WBZ events (D > $90 \mathrm{~km}$ ), the spatial distribution is not even. The density of events is higher in the bending parts of the WBZ than in the straight part of the WBZ (Figure 5).

The fault plane solutions for earthquakes occurring between September 1987 and March 1994 are based on $\mathrm{P}$ wave polarities reread by the authors. We used the program HYPOELLIPSE [ $L a h r, 1989]$ to locate the earthquakes and the program FPFIT [Reasenberg and Oppenheimer, 1985; J. Lahr, personal communication, 1996] to compute the fault plane solutions. From approximately 650 selected earthquakes, 180 were rejected 
because of poorly constrained fault plane solutions, resulting in a final data set of 470 . The average number of first motions per event is 27 . For shallow and intermediate depth events it is essential to use a velocity model with continuously increasing velocity (one dimensional) with depth to obtain good quality fault plane solutions. The criteria used for selecting high-quality focal mechanisms are as follows: (1) the numbers of first motions per event must be at least 20; (2) the number of inconsistent polarities must be smaller than 3 ; (3) focal mechanisms must be unique for a single event (i.e., no multiple solutions are permitted); and (4) the errors in the strike, dip, and rake must be smaller than $20^{\circ}$. For most earthquakes with $M_{L} \geq 3$, useful fault plane solutions were obtained. In the range $2.5<M_{L}<3.0$ the success rate varied, with better results for the deeper events. The formal errors of hypocenters of the events are $0.9 \pm 0.6 \mathrm{~km}$ horizontally and $2.8 \pm 1.3 \mathrm{~km}$ vertically. The formal errors of strike, dip, and rake of the focal mechanism solutions are $7^{\circ} \pm 6^{\circ}, 7^{\circ} \pm 6^{\circ}$, and $10^{\circ} \pm 8^{\circ}$, respectively.

The second part of our data set is composed of 38 focal mechanisms from the Harvard Centroid Moment Tensor catalog and 29 fault plane solutions from Bhattacharya and Biswas [1979] and Estabrook et al. [1988]. The average magnitude for these 67 earthquakes is 4.8

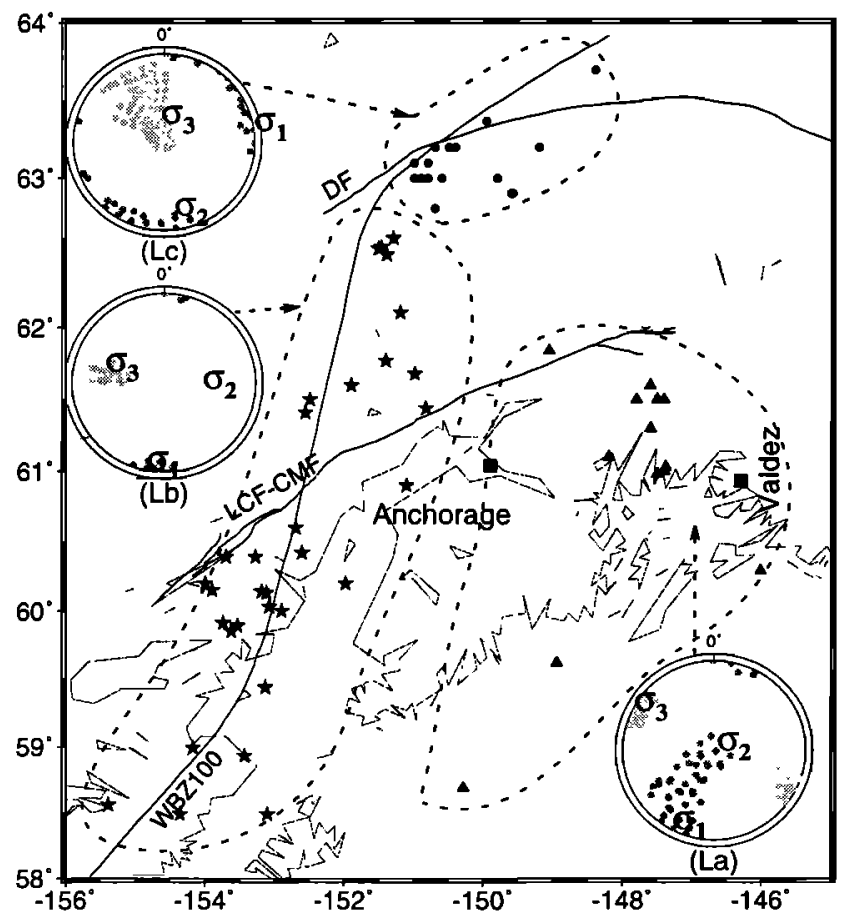

Figure 7. Epicenter map of large earthquakes $\left(M_{s} \sim\right.$ 5) with fault plane solutions in Alaska and stereographic projection of the best fitting principal stress directions for shallow WBZ events (triangles, set La in Table 1) and intermediate and deep WBZ earthquakes (stars, set Lb; dots, set Lc in Table 1). The $95 \%$ confidence regions are defined by heavily and lightly shaded dots for the greatest and least principal stress, respectively. \pm 0.7 . These large events are located in the WBZ. Out of 67 events, 15 are located in the shallow part of the WBZ $(D<40 \mathrm{~km})$, and 52 are in the intermediate and deep parts of the WBZ $(55<\mathrm{D}<140 \mathrm{~km}$ ) (Figure 7). These events occurred during the period of 1972 to 1995.

\section{Analysis}

Large earthquakes in the WBZ. Inverting the entire set of large events (set $L$ in Table 1), we find a misfit of $F=8.5^{\circ}$ too large to be accepted on the basis of our criteria. Because the cumulative misfit method is presently only applicable to one-dimensional analysis, we did not investigate the stress heterogeneity using the cumulative misfit method for this data subset. By trial and error analysis, we divided the large events into three subsets ( $\mathrm{La}, \mathrm{Lb}$, and Lc, Figure 7). We obtained average misfits of $3.3^{\circ}, 4.0^{\circ}$, and $5.0^{\circ}$ for volume $\mathrm{La}, \mathrm{Lb}$, and $L c$, respectively. These misfits are small enough to satisfy our criterion for acceptably homogeneous data sets. Thus we did not further subdivide the data set for large earthquakes. The constraints (i.e., $95 \%$ confidence regions) of these results do not overlap, and so they can be accepted as meaningful (Figure 7, sets La, Lb, and Lc in Table 1).

An invalid stress tensor may be obtained if the data are composed of sets from more than one volume with significantly different stress orientations, and this solution may not readily be identified as incorrect. Inverting the 48 large earthquakes (set Ld, Table 1) by combining set $\mathrm{La}$ and set $\mathrm{Lb}$ yields the same stress tensor as the one obtained by inverting set $\mathrm{Lb}$ with an average misfit of $6.9^{\circ}$. After subdividing the 48 earthquakes into two subsets, we find the stress tensor in set $\mathrm{La}$ is significantly different from that in set $\mathrm{Lb}$ based on both $\mathrm{z}$ test and distributions of the $95 \%$ confidence limits of the greatest and the least principal stresses, and the average misfits in set $\mathrm{La}$ and $\mathrm{Lb}$ are reduced to $3.0^{\circ}$ and $4.0^{\circ}$, respectively.

Small earthquakes in the crust. The small crustal earthquakes (D $<40 \mathrm{~km}$ ) separate into two clusters located near Mount McKinley (cluster 1) and in the area near the apex of the Denali fault and Fairbanks, cluster 2 (Figure 6). As a first subdivision we selected these two sets on the basis of geographic distribution. The average misfits for clusters 1 and 2 (Figure 6) are smaller than $10.2^{\circ}$, the average misfit obtained by using all small shallow earthquakes (set S0, Table 1), but they are too large to be accepted as homogeneous: $7.5^{\circ}$ and $8.7^{\circ}$ (sets 1 and 2, Table 1), respectively. By trial and error we subdivided set 2 into a northern and southern part, finding no dividing line that leads to an acceptable misfit for the southern part $\left(F=8.9^{\circ}\right.$, set $2 \mathrm{~S}$, Table $1)$. Thus we cannot define the stress directions at the northern apex of the Denali fault (dots in Figure 6). In the area near Fairbanks the stress directions are well constrained (diamonds in Figure 6) and the misfit is small $\left(F=3.8^{\circ}\right.$, set $2 \mathrm{~N}$, Table 1$)$. 

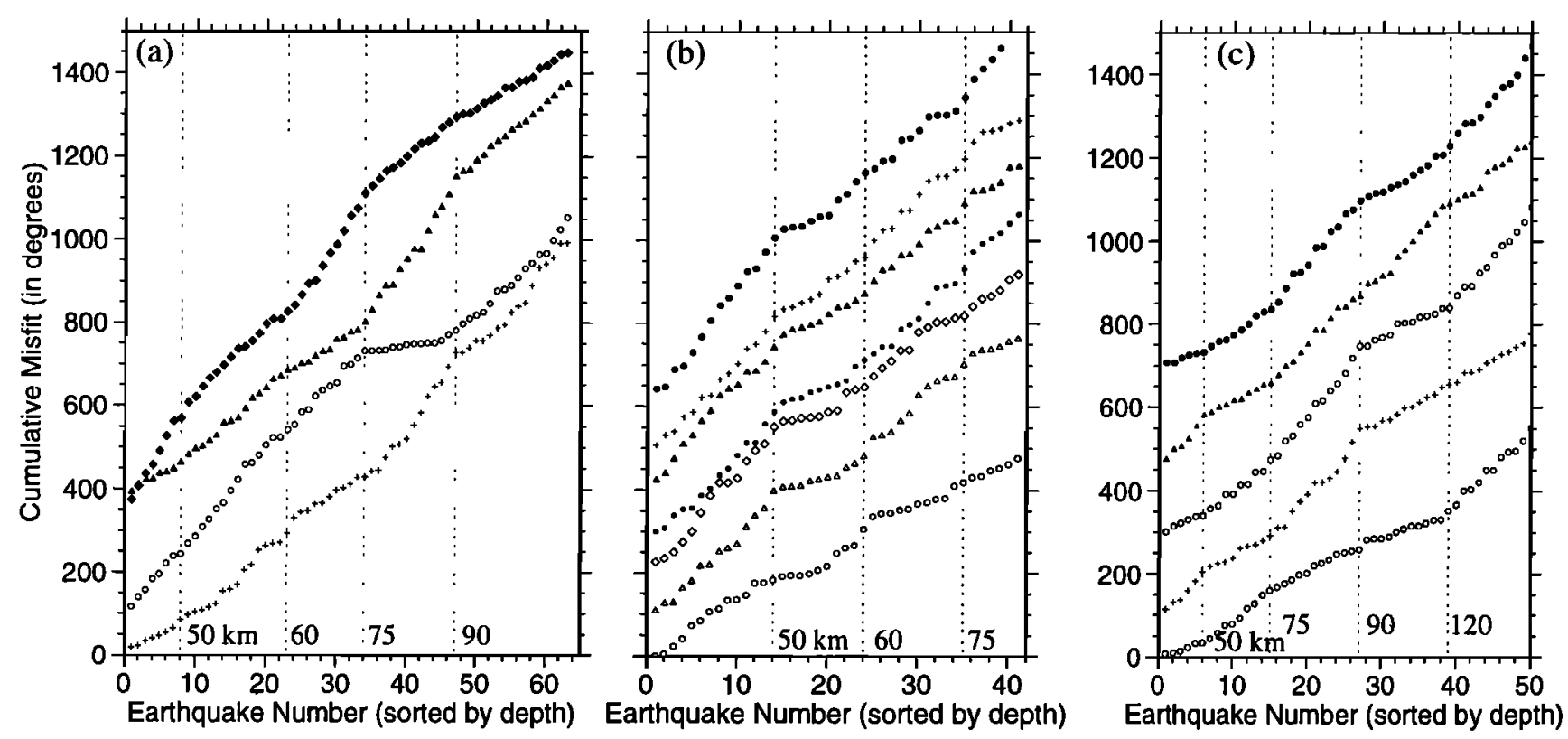

Figure 8. Cumulative misfit as a function of depth in (a) polygon 1, (b) polygon 2, and (c) polygon 3, defined in Figure 5. The depths at which stress directions change are indicated by vertical dashed lines. The curves with different symbols are based on several different test stress tensors for assumed stress directions. All but the bottom curve have been shifted upward for clarity.

When shallow earthquake cluster 1, near Mount McKinley, was subdivided, we found two sets with acceptably small average misfits (sets $1 \mathrm{~W}$ and $1 \mathrm{E}$, Table 1). However, the result for the eastern part (set $1 \mathrm{E}$, Table 1) is so poorly constrained (Figure 13) that we do not accept the solution as meaningful.

Small earthquakes in the WBZ. We separately inverted the fault plane solutions of the 19 earthquakes (D $\leq 40 \mathrm{~km}$ ) located near Valdez (Figure 5) because these events are widely separated from the other WBZ earthquakes. The inversion of the data yields $F=$ $3.3^{\circ}$ (set 3 , Table 1 ), which equals approximately the smallest values we have found in other data sets [Liang and Wyss, 1991; Gillard et al., 1992, 1996; Gillard and Wyss, 1995; Lu and Wyss, 1996]. This suggests that the quality of the Alaskan fault plane solutions is comparable to those in Hawaii, California, Iran, and the Aleutians.

We subdivided the bulk of our data, the remaining 403 small subcrustal earthquakes $(40<D<140 \mathrm{~km})$, using the cumulative misfit method [Wyss and $L u, 1995$; Lu and Wyss, 1996]. Because this method is currently applicable for one-dimensional analysis only, we had to decide whether to search for segmentation as a function of depth or distance along strike of the seismic zone first. On the basis of preliminary exploration we decided to first define subdivisions in three profiles as a function of depth (Figure 5), because the contrasts in this direction are expected to be strongest. The cumulative misfit curves as a function of depth for the three regions (Figure 5) are shown in Figure 8. The changes of the slopes in the cumulative plot are interpreted as boundaries in the stress directions. The boundaries suggested by several cumulative curves in Figures $8 \mathrm{a}, 8 \mathrm{~b}$, and $8 \mathrm{c}$ are at $50,60,75,90$, and $120 \mathrm{~km}$ depths. We use the average estimates of changes of stress directions from several stress tensors as the segmentation boundaries. Because of the limitation of the number of earthquakes in our analyses, some of the boundaries suggested by the cumulative misfit curves are not selected (e.g., around earthquake numbers 20 and 30 in Figure $8 \mathrm{~b}$ ). All but the $120-\mathrm{km}$-depth boundary are confirmed by results in more than one profile.

The final step in the search for stress boundaries was to plot the cumulative misfit curves as a function of strike from south to north in each of the depth bands $40-50,50-60,60-75,75-90,90-120$, and $120-140 \mathrm{~km}$. As an example we show the misfit curve for the depth band 120-140 km (Figure 9). In this example the cumulative misfit angle, as a function of distance along strike of the WBZ based on seven test stress tensors, suggests that two stress boundaries exist, dividing the data set into three segments with reasonably uniform misfits. Also the three separate samples happen to contain approximately the same number of events, $N=19 \pm 1$, which is large enough, in general, to yield stable inversion solutions. The separate inversion of the three subsets at depths $120-140 \mathrm{~km}$ leads to misfits of $3.8^{\circ}, 5.0^{\circ}$, and $5.5^{\circ}$ (sets 9a, 9b, and 9c in Table 1), whereas the inversion using all the earthquakes in this depth range produced $F=10.4^{\circ}$. This reduction (a factor of 2 to 3 ), from an unacceptably large average misfit to small 


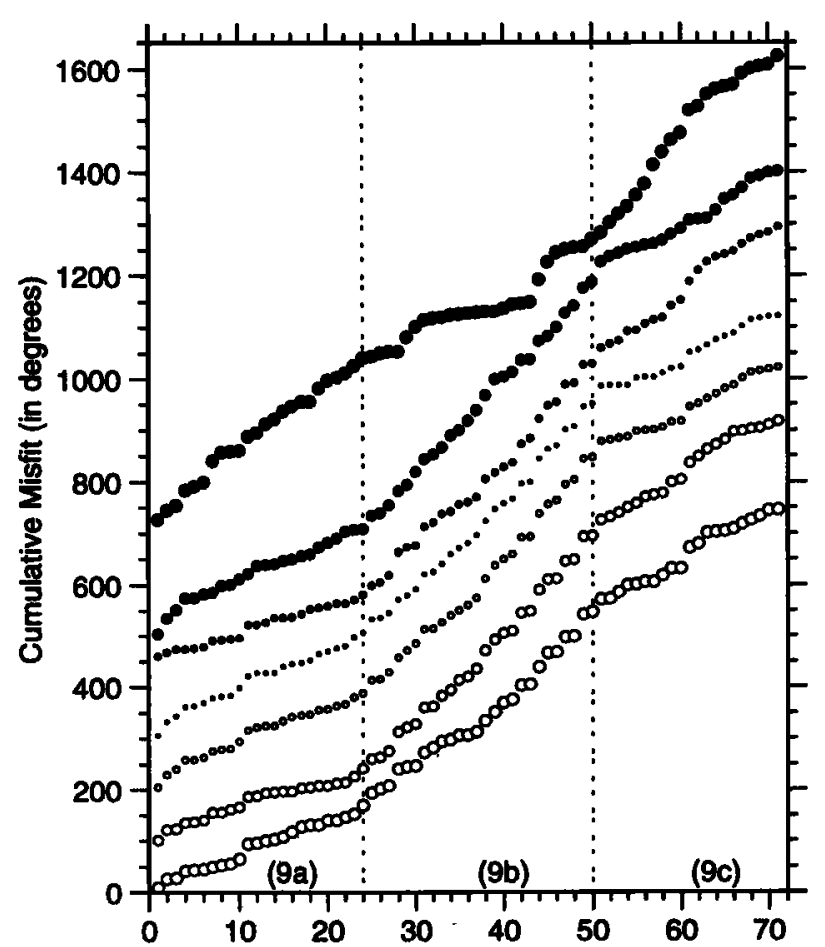

Earthquake Number (sorted by distance along the strike)

Figure 9. Cumulative misfit as a function of strike at depth 120-140 km using seven different test stress tensors. The changes of stress direction estimated around event numbers 24 and 50 separate the data set in this depth range into three sets (sets $9 \mathrm{a}, 9 \mathrm{~b}$, and 9c, Table1). Their principal stress orientations are shown in Figure 10. All but the bottom curve have been shifted upward for clarity.

values, confirms that our method of selecting homogeneous data sets by cumulative misfit curves is effective. On the basis of geographical distribution of epicenters in this case, we would not have chosen the boundaries found by our technique (Figure 10).

The reduction of the average misfit in this example is typical for all depth intervals. The overall data sets for each depth range tended to result in approximately $F$ $=10^{\circ}$, whereas the subsets selected by our method had $3.2^{\circ} \leq F \leq 5.5^{\circ}$ (except for two cases with $F=6.1^{\circ}$ and $F=7.3^{\circ}$, Table 1). In some cases, several events located near the segmentation boundaries are excluded from the final inversions of both neighboring segments because these events do not fit either of the stress tensors of the neighboring segments. For some of the subsets the constraint of the principal stress axes was unsatisfactory (e.g., the northern set in the depth range $40-50 \mathrm{~km}$, Figure 11; the data near $61^{\circ} \mathrm{N}$ in the depth range 50-60 $\mathrm{km}$, Figure 12). The results for these subsets are shown in Figure 13.

\section{Results and Discussion}

Stress directions in the Alaskan WBZ. For the large earthquakes (67 events), only two divisions into three subsets were necessary to reduce the misfit from an unacceptably large value of $8.5^{\circ}$ to $3.3^{\circ}$, $4.0^{\circ}$, and $5.0^{\circ}$ in the three subsets. These misfit values indicate that stress directions can be interpreted as homogeneous in these volumes. The data set of small earthquakes had to be subdivided into 25 subsets for satisfying the condition of homogeneity. For 20 of these data sets the inversions yielded meaningful results with reasonably well constrained stress directions. The estimated stress directions show some similarities, but some of them also differ significantly based on the distribution of the $95 \%$ confidence regions of the greatest and least principal stresses. They reveal a picture of complex stress orientations in the subducting slab under Alaska, especially in and near its pronounced bend.

There are 15 large shallow WBZ earthquakes with fault plane solutions in Alaska. The orientations of the principal stresses (set La in Table 1 and Figures 7 and 14) seem acceptable because the least principal stress is well constrained. Epicenters of most of these events are scattered in the region between Anchorage and Valdez

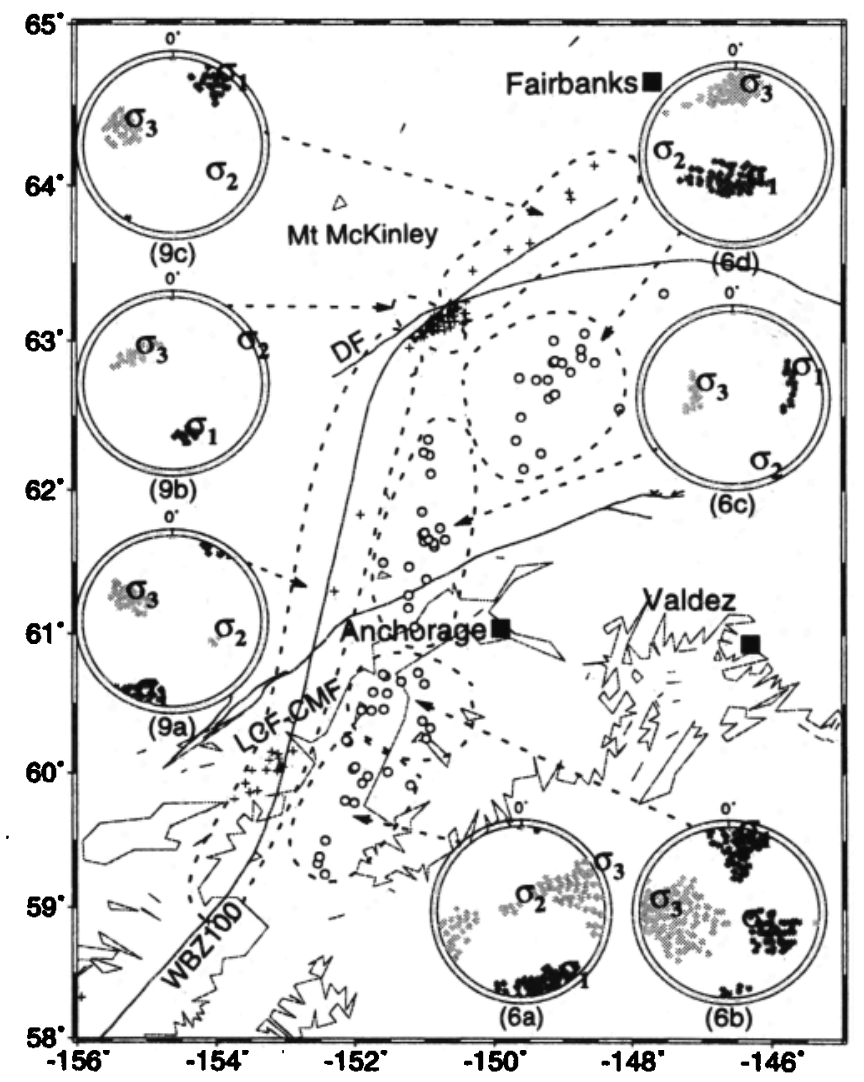

Figure 10. Epicenter map of small subcrustal earthquakes in the depth ranges $120-140 \mathrm{~km}$ (crosses) and 60$75 \mathrm{~km}$ (circles), together with stereographic projections of the best fitting principal stress directions for subsets selected on the basis of cumulative misfit slopes. The subset numbers correspond to those in Table 1. Dashed contours outline the extent of the data sets. Inversions of data from earthquakes whose epicenters are not encircled by a dashed line do not yield meaningful results. 


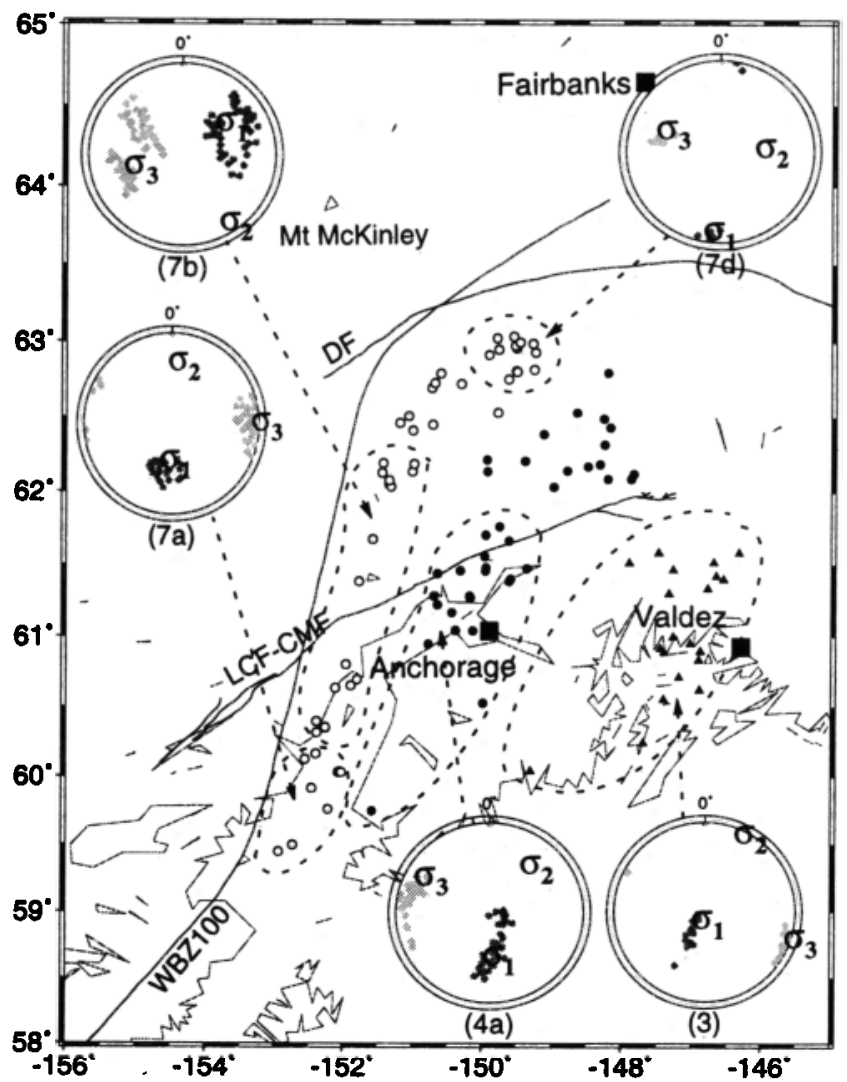

Figure 11. Epicenter map of small subcrustal earthquakes in the depths ranges $75-90 \mathrm{~km}$ (open circles), $40-50 \mathrm{~km}$ (solid circles), and $0-40 \mathrm{~km}$ (triangles), together with stereographic projections of the best fitting principal stress directions for subsets selected on the basis of cumulative misfit slopes (same as Figure 10).

(Figure 7). For approximately the same area we have a data set of 19 small earthquakes that also define a normal to strike-slip faulting regime (set 3 , Table 1 and Figures 11 and 14). The $\sigma_{3}$ axes defined from both large and small earthquakes are oriented horizontally, striking $\mathrm{N} 56^{\circ} \pm 3^{\circ} \mathrm{W}$. Although the data are scant, the evidence is clear that in the area between Anchorage and Valdez a stress regime exists with least principal stress striking WNW horizontally. The plunge of the least principal stress, $2^{\circ}-5^{\circ}$, is consistent with the gentle dip direction of the WBZ, $6^{\circ}-7^{\circ}$, reported by Page et al. $[1989,1991]$.

The stress directions in the WBZ below $40 \mathrm{~km}$ present a simple picture if defined by large earthquakes only but a more complex one if estimated from small earthquakes. In the latter case, different stress directions are found in most volumes with homogeneous stress orientation. The dimensions of these volumes are typically 10 to $30 \mathrm{~km}$ in depth and 50 to $100 \mathrm{~km}$ along strike (Figure 14). An unusual feature of the solution derived from the large earthquake data set is that the orientation of the greatest principal stress is parallel to the strike of the WBZ. This is unusual because the typical fault plane solution in deep seismic zones has the intermediate stress direction aligned along strike. The stress orientation derived from the large earthquakes is confirmed by the general trend observed in the stress orientations derived from the small earthquake data set. Seventy percent of the 18 separate inversion results show the least principal stress axis pointing essentially downdip of the WBZ, and $60 \%$ have the greatest principal stress oriented approximately horizontal and in the strike direction of the WBZ (Figure 14, Table 1). From this we conclude that the basic force of a sinking slab, causing the orientation of $\sigma_{3}$ in the classical downdip direction, is modified by the presence of the major bend in the WBZ. Along an axis roughly from Palmer to Mount McKinley the Alaskan WBZ changes strike by $35^{\circ}$ (Figure 14). That portion of the bend with the greatest curvature is also associated with a cluster of seismic activity, particularly in the depth range from 90 to $140 \mathrm{~km}$. In spite of the large number of events available and several subdivisions, it was not possible to resolve the stress in most volumes associated with the cluster.' We believe that this is due to the very rapid spatial stress changes in this portion of the bend, rendering the subvolumes heterogeneous. The existence of this cluster is possibly a further indication of rapidly changing stresses.

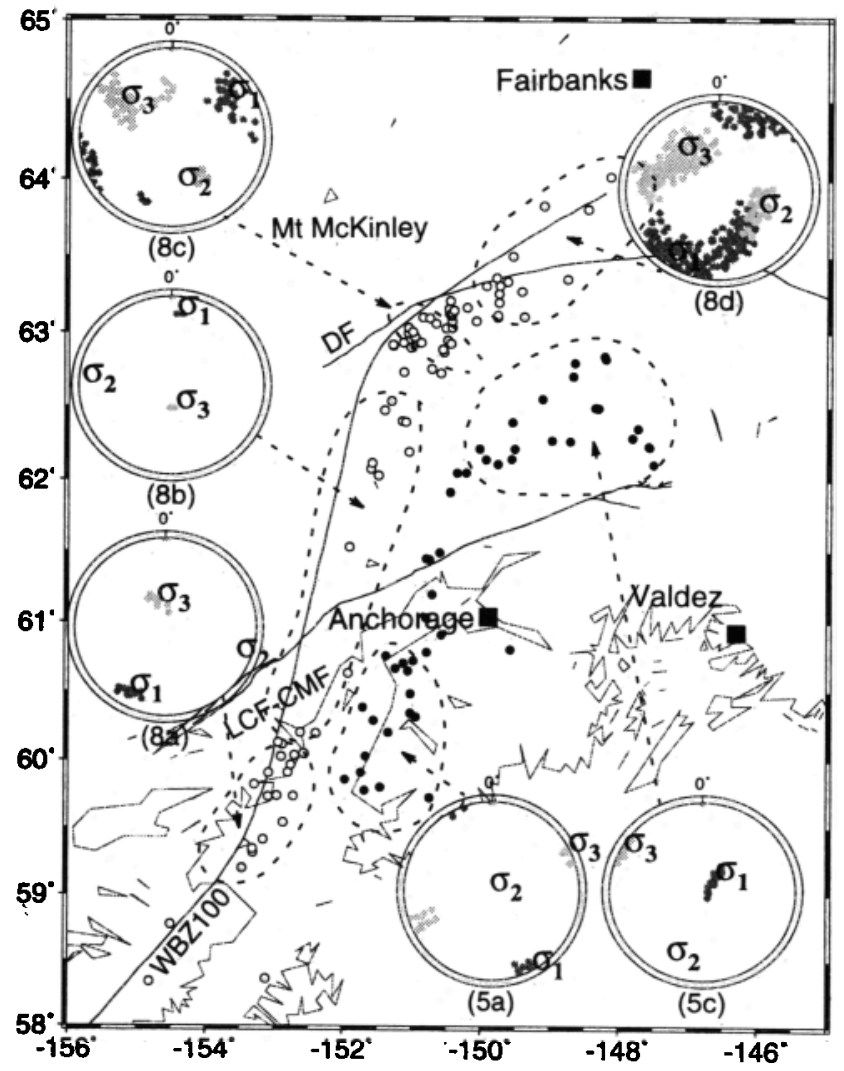

Figure 12. Epicenter map of small subcrustal earthquakes in the depths ranges $90-120 \mathrm{~km}$ (open circles) and $50-60 \mathrm{~km}$ (solid circles), together with stereographic projections of the best fitting principal stress directions for subsets selected on the basis of cumulative misfit slopes (same as Figure 10). 

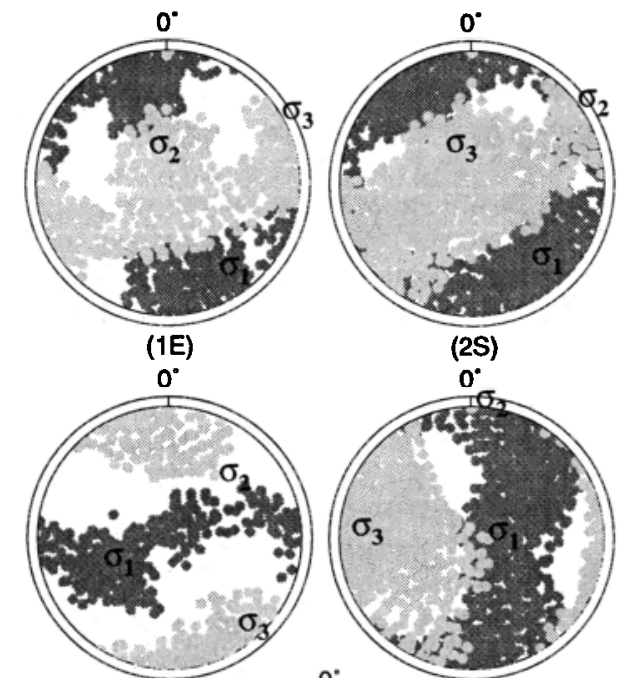

$0^{*}$

(4b)

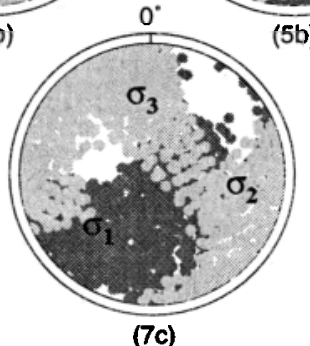

(5b)

(7c)

Figure 13. Stereographic projections of the principal stress direction estimates for inversions that did not yield meaningful results. The epicenters of these earthquakes are shown in Figures 6, 11, and 12. The 95\% confidence regions are defined by heavily and lightly shaded dots for the greatest and least principal stresses, respectively.

Along-strike compression in the WBZ below Cook Inlet has also been observed by Lahr [1975], Engle [1982], Pulpan and Frohlich [1985], and Lahr et al. [1993, 1994]. Creager and Chiao [1992] obtained along-strike compression from three-dimensional convective flow modeling of a Pacific slab subducting underneath Alaska. The along-strike compression is explained by the "tablecloth effect" [Creager and Chiao, 1992]. In their model, Creager and Chiao [1992] showed that the geometry of the Pacific slab is similar to that of a table cloth draped over the corner of a table. Since the table cloth (Pacific plate) is smooth when lying on the table, a fold of extra material develops when it is pushed past the edge over a table corner. The presence of this extra material in the corner has to be accommodated and translates into horizontal compressive stress within the deep slab away from the bend [Creager and Chiao, 1992].

Out of the 23 volumes within which we had enough earthquakes to locally define the stress directions, five showed unacceptable results (areas shaded in Figure 14). Either the average misfits or the confidence areas were too large to be accepted as meaningful. Most of the remaining 18 solutions were statistically different from each other at the $95 \%$ significance level. In the stereographic projections the areas of the confidence

levels of one or two principal axes do not overlap. Some of these differences are pronounced, resulting in a generally heterogeneous picture of stress directions (Figure 14). Nevertheless, there are some parts of the WBZ in which neighboring solutions are similar. For example, near the deeper northern end of the $\mathrm{WBZ}$ volumes $7 \mathrm{~d}$, $8 \mathrm{~d}$, and $9 \mathrm{c}$ show enough similarity that one may consider them approximately the same (Figures 10, 11, 12, and 14).

In the Aleutian WBZ, complexity of stress directions similar to those we found probably exist as well. Reyners and Coles [1982] subdivided their data set of first motions into five subsets in order to obtain reasonably consistent patterns for composite fault plane solutions for small earthquakes in the WBZ of depths between 50 and $250 \mathrm{~km}$ beneath the Shumagin Islands.

We conclude that the basic stress field of downdip extension is modified throughout the WBZ under Alaska. The modification is most pronounced in the bend of the strike. Within the bend, volumes with dimension of 10 to $20 \mathrm{~km}$ do not satisfy the condition of homogeneity necessary for inversion of the stress directions (e.g., shaded volumes among sets 8b, 8c, and 8d in Figure 14). The presence of the bend makes itself known by the generation of horizontally compressive stresses along strike of the entire WBZ under Alaska. In addition, local perturbations of the stress field exist within the WBZ in volumes with dimensions of a few tens of kilometers.

Stress directions in the crust. In the area within about 100-km radius around Fairbanks a set of 16 earthquakes (set $2 \mathrm{~N}$ in Table 1 and Figure 14) defines a stress orientation of strike-slip type, with the greatest principal stress striking approximately NS. The small misfit, $F=3.8^{\circ}$, indicates homogeneity, whereas the adjacent 19 earthquakes to the south (set $2 S$ in Table 1 and Figures 6 and 13) do not fit this solution, nor could a useful solution be obtained using only the southern subset.

The stress directions in the earthquake cluster within a 20-km radius near Mount McKinley are heterogeneous as a whole but can be defined as of thrusting type in the western part, with the greatest principal stress oriented about NW, perpendicular to the local strike of the Denali fault (set $1 \mathrm{~W}$ in Table 1 and Figures 6 and 14). Inversions of the data from the eastern part of this cluster (set $1 \mathrm{E}$ in Table 1) did not lead to meaningful results, as the stress directions were too poorly constrained (Figure 13). We compared the uncertainties of fault plane solutions in set $2 \mathrm{~S}$ with $2 \mathrm{~N}$ and in set $1 \mathrm{~W}$ with $1 \mathrm{E}$. No differences could be found. Therefore we conclude that the poorly constrained principal stress directions are not caused by the errors in the focal mechanism data. We interpret the stress directions in the areas under Mount McKinley and in 2S as changing rapidly as a function of space, but we do not have enough earthquakes to define them.

The orientation of the near-horizontal greatest principal stress is perpendicular to the Alaska range, rang- 


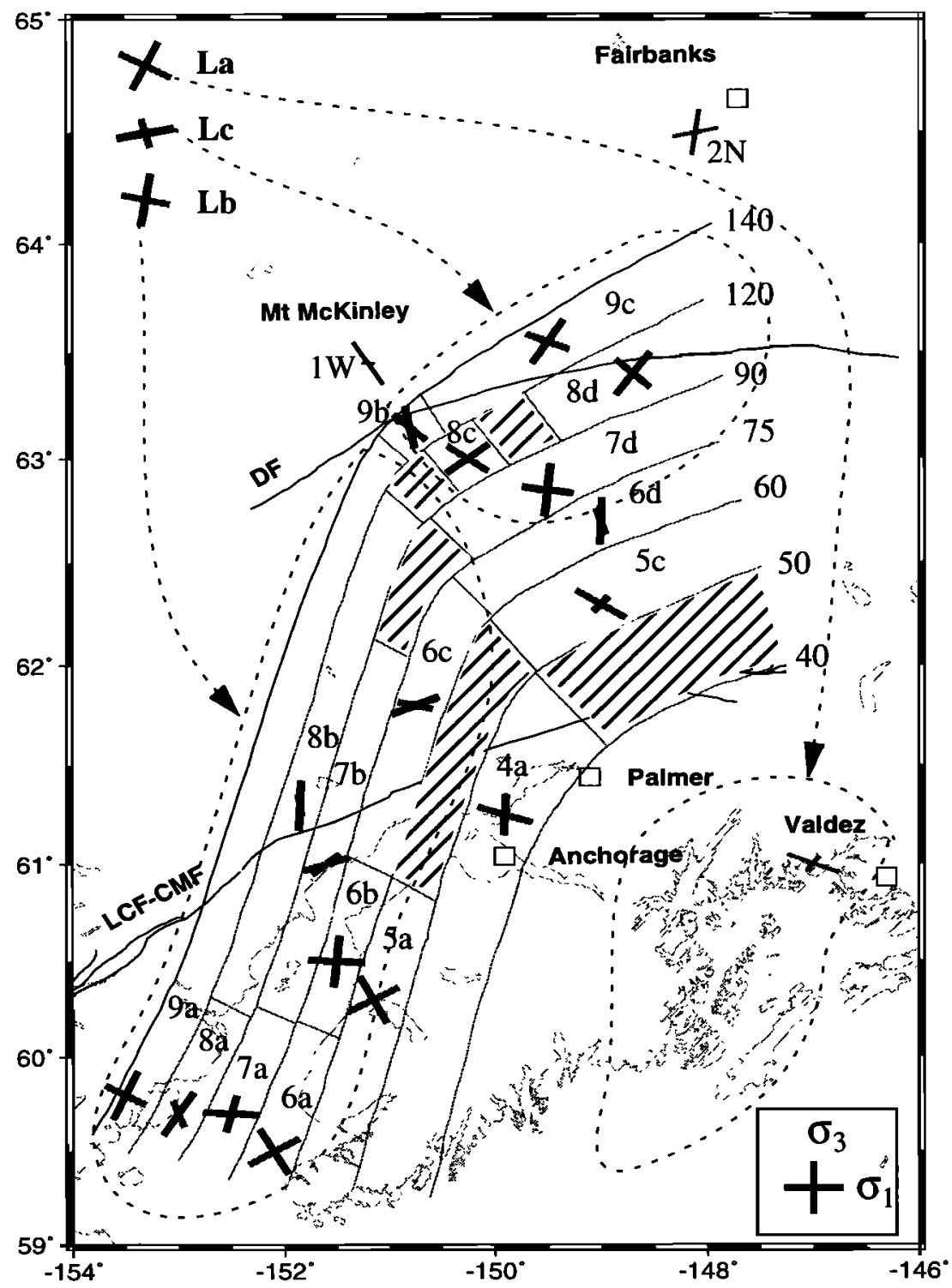

Figure 14. Map of stress directions in Alaska in the crust (thin bars) and in the subducting slab (thick bars) based on inversions of fault plane solutions of $M_{L} \sim 3$ earthquakes. The length of solid bars ( $\sigma_{1}$ direction) and gray bars ( $\sigma_{3}$ direction) are proportional to their dip with full length for horizontal (example at lower right) and zero length for vertical dip. The deviations of $\sigma_{1}$ and $\sigma_{3}$ at the $95 \%$ confidence level can be found in the corresponding stereographic projection plots in Figures 6, 7, 10, 11, and 12. The data set numbers are those used in Table 1. The boundaries within which each pair of stress directions is valid are defined by the lines of depth contours. In shaded volumes, inversion attempts did not lead to meaningful results. The stress directions derived from the large earthquakes, shown at the top left, are valid for the Anchorage-Valdez (La) and the southern (Lb) and northern (Lc) parts of WBZ.

ing in directions from NNE near Fairbanks to NW near Mount McKinley. This is what one might expect from the topography of the young mountain belt of the Alaska range. The stress tensor solution near Fairbanks obtained from small earthquakes (set 2N, Figure 6) is consistent with the few poorly known fault plane solutions of historic large earthquakes in that area [e.g., Gedney et al., 1980; Estabrook et al., 1988; Page et al., 1995; Fletcher and Christensen, 1996]. The collision of the Pacific and American plates is most likely responsible for these stresses.
Stress indicators derived from volcanic dikes reported by Nakamura et al. [1977] are located in areas where we have no data. Their estimate of greatest principal stress orientation of NNW at Mount Spurr (Figure 6), west of Anchorage, agrees with that by Jolly et al. [1994] based on inversion from focal mechanisms of very small earthquakes near that volcano. In the rest of Alaska, only very approximate estimates of stress directions based on surface faulting are available [Brogan et al., 1975; Bird, 1996]. These require assumptions in some cases that render the estimates quite uncertain. Neverthe- 
less, they agree with our results in those areas where we have information (Mount McKinley, Fairbanks). It is unfortunate that we have very few fault plane solutions for crustal earthquakes in Alaska. We urgently need more for defining the stress field between Anchorage and Fairbanks as well as along the Denali fault. More high-quality fault plane solutions could be obtained if a regional broadband network of seismographs was operated in Alaska.

\section{Scale of the Stress Field and Size of Earthquake Ruptures}

Large earthquakes can give information about the large-scale stress field only, because their rupture dimensions are too large to sense small-scale variations in stress directions. Small ruptures, on the other hand, could occur in response to the same large-scale stress field, but they could alternatively occur in response to a locally perturbed stress field. Therefore one should not assume a priori that earthquakes of greatly varying size constitute a homogeneous sample [e.g., Caccamo et al., 1997]. This assumption should be tested by inverting the small and large earthquakes in a common area separately. We found that for the area between Anchorage and Valdez, inversion of large and small earthquakes from the same volume yielded approximately the same stress tensor. In this case, we argue that both results are valid, they confirm each other, and the large as well as the small earthquakes respond to the regional (dimension of $100 \mathrm{~km}$ ) stress field.

In the WBZ below $40 \mathrm{~km}$ we found well-constrained stress directions for the large earthquakes with a satisfactorily small misfit. Since these shocks were distributed in most of the WBZ, we accept that result as valid for the WBZ under Alaska as a whole. In contrast, the 384 small earthquakes in the WBZ had to be subdivided into 21 subsets to satisfy our criteria for satisfying the assumption of homogeneity. Most of the 18 wellconstrained results showed significant differences from each other and from the overall solution based on the large events. We conclude that the large-scale stress directions in the WBZ measured by the large events are seemingly uniform but that a great deal of stress perturbations exist in the descending slab at smaller scales, which can only be resolved by inversion of fault plane solutions from small earthquakes.

The rupture dimensions of the small earthquakes we used $\left(M_{L} \sim 3\right)$ are a few hundred meters, approximately. The dimensions of the volumes within which we found homogeneity vary from about 10 to $100 \mathrm{~km}$. The ruptures of the large earthquakes we used are approximately $10 \mathrm{~km}$ long $\left(M_{s} \sim 5\right)$, whereas the stress field sensed by these events seems to be homogeneous over 300-km dimensions. For small earthquakes in Hawaii $\left(M_{L} \sim 3\right)$, homogeneity in cubes of the crust with dimensions of about $10 \mathrm{~km}$ was found [Gillard et al., 1992, 1996], whereas in Iran, homogeneity in volumes ranging up to $1000 \mathrm{~km}$ length was found when studying ruptures longer than $20 \mathrm{~km}\left(M_{s}>6\right)$ [Gillard and Wyss, 1995]. The ratio of the dimensions of the homogeneous stress field to the ruptures in all of these cases is similar and approximately 20 to 50 . We therefore propose that in inversion of fault plane solutions for stress directions, as performed here, one estimates the stress field in general in an area with dimensions about 20 to 50 times larger than the rupture dimensions of the earthquakes. Also, small earthquakes have the alternate option to sense the overall stress field that has dimensions more than 100 times larger than their ruptures.

\section{Conclusions}

The cumulative misfit method proposed by Wyss and $L u$ [1995] and $L u$ and Wyss [1996] is capable of defining segments with homogeneous stress directions along major fault systems or plate boundaries. Both, the results from the test on synthetic data sets and the application to data from the Alaska WBZ, indicate that the method permits defining regions with homogeneous stress directions. This does not mean the method will always succeed. In its present form, the cumulative misfit method is best suited for application to "belts" of seismicity where the earthquakes are narrowly distributed along a major tectonic feature such as a fault or plate boundary. A logical next step is to adapt the method for a situation where the seismicity is distributed diffusely over a wide area. Also, we found one area where very rapid stress changes made it impossible to obtain subvolumes with sufficient numbers of fault plane solutions to resolve the stress tensor orientation and where the cumulative misfit method did not provide information about additional segmentation.

The criteria for accepting a stress tensor, obtained from inverting earthquake focal mechanisms, are (1) the average misfit of the inversion is less than $6^{\circ}$ [Wyss et al., 1992; Gillard et al., 1996] and (2) the 95\% confidence regions of the greatest and least principal stress directions are well constrained. Applying the cumulative misfit method to the Alaska WBZ, we found that the average misfit of at least one of the two new data sets was reduced after dividing a data set. The most typical result of subdividing, using this method, was that $F$ of both subsets were reduced by about a factor of 2 . Therefore we conclude that this is a useful method for finding discontinuities in stress directions.

The smallest misfit that can be found in a subset should be calculated in any study of inversion for stress directions, as a gauge of the quality of the fault plane solutions. In Alaska the smallest misfits were about 3.2, suggesting that the quality of the fault plane solutions in Alaska is comparable to those in Hawaii, California, Iran, and the Aleutians.

The estimated stress directions of the crustal earthquakes corresponded to the following mechanisms: (1) strike-slip faulting with the greatest principal stress ori- 
ented NS near Fairbanks and (2) thrusting with the greatest principal stress oriented NW-SE near Mount McKinley.

Stress directions along the Alaska WBZ are based on 470 small WBZ earthquakes $\left(M_{L} \sim 3\right)$, ranging in depth from the surface to $140 \mathrm{~km}$, and 67 larger earthquakes $\left(M_{s} \sim 5\right)$ with known fault plane solutions. For the large earthquakes, only two divisions into three subsets were necessary to reduce the misfit from an unacceptably large misfit to misfits which indicate that stress directions are homogeneous in the subsets. The data set of small earthquakes had to be subdivided into 25 subsets to satisfy the condition of homogeneity. For 20 of these data sets the inversions yielded meaningful results with reasonably well constrained stress directions. The stress directions measured by the large earthquakes $\left(M_{s} \sim 5\right)$ were homogeneous, with extension downdip and the direction of greatest compression along strike. This unusual orientation of the greatest principal stress is attributed to the bend of the slab under central Alaska, which generates compressive stresses along strike. McGuire and Wiens [1995] obtained a similar observation in the new Britain subduction zone. The stress orientations revealed by small earthquakes, in contrast, exhibited a great deal of heterogeneity as a function of space, although they show a trend that confirms the overall stress directions obtained from the large events. We propose that the ratio of the dimensions of the stress field sensed by earthquakes to the rupture dimensions is about 20 to 50 .

Acknowledgments. We thank G. Abers, E. Kissling, and an anonymous referee for the comments and suggestion which greatly improved the manuscript. We thank R. Page for critical suggestions and carefully reading the manuscript. We also thank J. Lahr, D. Christensen, S. McNutt, J. Freymueller, J. Beniot, S. Wiemer, and A. Allmann for helpful comments. This work was supported by the National Science Foundation under grant 9118086 and in part by the Wadati endowment at the Geophysical Institute of the University of Alaska.

\section{References}

Angelier, J., Determination of the mean principal directions of stresses for a given fault population, Tectonophysics, 56, T17-T26, 1979.

Beroza, G. C., and M. D. Zoback, Mechanism diversity of the Loma Prieta aftershocks and the mechanics of mainshock-aftershock interaction, Science, 259, 210-213, 1993.

Bhattacharya, B., and N. N. Biswas, Implications of north Pacific plate tectonics in central Alaska: Focal mechanisms of earthquakes, Tectonophysics, 53, 99-130, 1979.

Bird, P., Computer simulations of Alaskan neotectonics, Tectonics, 15, 225-236, 1996.

Bott, M. H. P., The mechanics of oblique slip faulting, Geol. Mag., 96, 10 9-117, 1959.

Brogan, G. E., L. S. Cluff, M. K. Korringa, and D. B. Slemmons, Active faults of Alaska, Tectonophysics, 29, 73-85, 1975 .
Caccamo, D., G. Neri, A. Sarar, and M. Wyss, Estimates of stress directions by inversion of earthquake fault plane solutions in Sicily, Geophys. J. Int., in press, 1997.

Comte, D., and G. Suarez, An inverted double seismic zone in Chile: Evidence of phase transformation in the subducted slab, Science, 263, 212-215, 1994.

Creager, C., and T. M. Boyd, the geometry of Aleutian subduction: three-dimensional kinematic flow model, J. Geophys. Res., 96, 2293-2307, 1991.

Creager, C., and L. Y. Chiao, Membrane deformation rate and geometry of Aleutian Alaska subduction, in $W a-$ dat Conference on Great Subduction Earthquakes, edited by D. Christensen, M. Wyss, R. E. Habermann, and J. Davies, p. 27, Univ. of Alaska, Fairbanks, 1992.

Creager, C., L. Y. Chiao, J. P. Winchester, and E. R. Engdahl, Membrane strain rates in the subducting plate beneath South Ameria, Geophys. Res. Lett., 22, 2321-2324, 1995.

Engle, K. Y., Earthquake focal mechanism studies of Cook Inlet area, Alaska, M.S. thesis, 81 pp., Univ. of Alaska, Fairbanks, 1982.

Estabrook, C. H., D. Stone, and J. N. Davies, Seismotectonics of northern Alaska, J. Geophys. Res., 93, 12026-12040, 1988.

Fletcher, H., and D. Christensen, A determination of source properties of large intraplate earthquakes in Alaska, Pure Appl. Geophys., 146, 21-41, 1996.

Gedney, L., S. Estes, and N. Biswas, Earthquake migration in the Fairbanks, Alaska, seismic zone, Bull. Seismol. Soc. Am., 70, 223-241, 1980.

Gephart, J. W., FMSI: A FORTRAN program for inverting fault/slickenside and earthquake focal mechanism data to obtain the original stress tensor, Comput. Geosci., 16, 953-989, 1990.

Gephart, J. W., and D. W. Forsyth, An improved method of determining the regional stress tensor using the earthquake focal mechanism data: Application to the San Fernando earthquake sequence, $J$. Geophys. Res., 89, 9305$9320,1984$.

Gillard, D., and M. Wyss, Comparison of strain and stress tensor orientation: Application to Iran and southern California, J. Geophys. Res., 100, 22197-22213, 1995.

Gillard, D., M. Wyss, and J. S. Nakata, A seismotectonic model for western Hawaii based on stress tensor inversion from fault plane solutions, J. Geophys. Res., 97, 6629$6641,1992$.

Gillard, D., M. Wyss, and P. Okubo, Type of faulting and orientation of stress and strain as a function of space and time in Kilauea's south flank, Hawaii, J. Geophys. Res., $101,16025-16042,1996$.

House, L. S., and K. H. Jacob, Earthquakes, plate subduction, and stress reversals in the eastern Aleutian arc, $J$. Geophys. Res., 88, 9347-9373, 1983.

Iguchi, M., K. Ishihara, and Y. Tatsumi, Characteristics of non-down-dip extensional intermediate-depth earthquakes immediately beneath the volcanic front in South Kyushu, Japan, Geophys. Res. Lett., 22, 1905-1908, 1995.

Isacks, B., and P. Molnar, Distribution of stresses in the descending lithosphere from a global survey of focal mechanism solution of mantle earthquakes, Rev. Geophys., 9, $103,1971$.

Isacks, B., J. Oliver, and L. R. Sykes, Seismology and the new global tectonics, J. Geophys. Res., 73, 5855-5899, 1968.

Jolly, A. D., R. A. Page, and J. A. Power, Seismicity and stress in the vicinity of Mount Spurr volcano, south central Alaska, J. Geophys. Res., 99, 15305-15318, 1994.

Jones, L. M., Focal mechanisms and the state of stress on 
the San Andreas fault in southern California, J. Geophys. Res., 93, 8869-8891, 1988.

Kissling, E., and J. C. Lahr, Tomographic image of the Pacific slab under southern Alaska, Eclogae Geol. Helv., 84, 297-315, 1991.

Lahr, J., Detailed seismic investigation of Pacific-North American plate interaction in southern Alaska, Ph.D. thesis, 88 pp., Columbia Univ., New York, 1975.

Lahr, J., HYPOELLIPSE/version 2.0: A computer program for determining local earthquake hypocentral parameters, magnitude, and first motion pattern, U.S. Geol. Surv. Open File Rep., 89-116, 92 pp., 1989.

Lahr, J., K. Fogleman, and R. Page, Stress within the Pacific plate of southern Alaska (abstract), Eos Trans. $A G U, 74$, 95, 1993.

Lahr, J., C. D. Stephens, R. Page, and K. Fogleman, Characteristics of the Aleutian Wadati-Benioff zone seismicity beneath southern Alaska, in SUBCON: An Interdisciplinary Conference on the Subduction Process, pp. 301303, U.S. Geol. Surv. Menlo Park, California, 1994.

Li, Z., N. Biswas, G. Tytgat, H. Pulpan, and M. Wyss, Stress directions along the Alaska Wadati-Benioff zone from inversion of focal mechanism data, Tectonophysics, 246, 163-170, 1995.

Liang, B., and M. Wyss, Estimates of orientation of stress and strain tensors based on fault plane solutions in the epicenter area of the great Hawaiian earthquake of 1868 , Bull. Seismol. Soc. Am., 81, 2320-2334, 1991.

Lu, Z., and M. Wyss, Segmentation of the Aleutian plate boundary derived from stress direction estimates based on fault plane solutions, J. Geophys. Res., 101, 803-816, 1996.

Matsuzawa, T., N. Umino, A. Hasegawa, and A. Takagi, Normal fault type events in the upper plane of the doubleplaned deep seismic zone beneath the northeastern Japan arc, J. Phys. Earth, 34, 85-94, 1986.

McGuire, J. J., and D. A. Wiens, A double seismic zone in New Britain and the morphology of the Solomon plate at intermediate depths, Geophys. Res. Lett., 22, 1965-1968, 1995.

McKenzie, D. P., The relationship between fault plane solutions for earthquakes and the directions of the principal stresses, Bull. Seismol. Soc. Am., 59, 591-601, 1969.

Michael, A. J., Determination of stress from slip data: Faults and folds, J. Geophys. Res., 89, 11517-11526, 1984.

Michael, A. J., Use of focal mechanisms to determine stress: A control study, J. Geophys. Res., 92, 357-368, 1987.

Nakamura, K., K. H. Jacob, and J. N. Davies, Volcanoes as possible indicators of tectonic stress orientation - Aleutians and Alaska, Pure Appl. Geophys., 115, 87-112, 1977.

Page, R. A., C. D. Stephens, and J. C. Lahr, seismicity of the Wrangell and Aleutian Wadati-Benioff zones and the north American plate along the trans-Alaska crustal tran- sect, Chugach Mountains and Copper River Basin, southern Alaska, J. Geophys. Res., 94, 16059-16082, 1989.

Page, R. A., N. N. Biswas, J. C. Lahr, and H. Pulpan, Seismicity of continental Alaska, Neotectonıcs of North America, Decade Map, Vol. 1, edited by D. B. Slemmons, E. R. Engdahl, M. D. Zoback, and D. D. Blackwell, Geol. Soc. of Am., Boulder, Colo., 1991.

Page, R. A., G. Plafker, and H. Pulpan, Block rotation in east-central Alaska: A framework for evaluating earthquake potential?, Geology, 23, 629-632, 1995.

Pulpan, H., and C. Frohlich, Geometry of the subducted plate near Kodiak Island and the lower Cook Inlet, Alaska, determined from relocated earthquake hypocenters, Bull. Seismol. Soc. Am., 75, 791-810, 1985.

Reasenberg, P., and D. Oppenheimer, Fortran computer programs for calculating and displaying earthquake fault plane solutions, U.S. Geol. Surv. Open File Rep., 85-739, 109 pp., 1985.

Rebai, S., H. Philip, and A. Taboada, Modern tectonic stress field in the Mediterranean region: Evidence for variation in stress directions at different scales, Geophys. J. Int., 110, 106-140, 1992.

Reyners, M., and K. Coles, Fine structure of the dipping seismic zone and subduction mechanics in the Shumagin Islands, Alaska, J. Geophys. Res., 87, 356-366, 1982.

Smith, S. W., J. S. Knapp, and R. C. McPherson, Seismicity of the Gorda plate, structure of the continental margin, and an eastward jump of the Mendocino triple junction, J. Geophys. Res., 98, 8153-8171, 1993.

Wiens, D. A., J. J. McGuire, and P. J. Shore, Evidence for transformational faulting from a deep double seismic zone in Tonga, Nature, 364, 790-793, 1993.

Wyss, M., and Z. Lu, Plate boundary segmentation by stress directions: Southern San Andreas fault, California, Geophys. Res. Lett., 22, 547-550, 1995.

Wyss, M., B. Liang, W. R. Tanigawa, and X. Wu, Comparison of orientations of stress and strain tensors based on fault plane solutions in Kaoiki, Hawaii, J. Geophys. Res., 97, 4769-4790, 1992.

Yin, Z.-M., and G. Ranalli, Determination of tectonic stress field from fault slip data: Toward a probabilistic model, J. Geophys. Res., 98, 12165-12176, 1993.

Zoback, M. D., and G. C. Beroza, Evidence for near-frictionless faulting in the 1989 ( $M$ 6.9) Loma Prieta, California, earthquake and its aftershocks, Geology, 21, 181-185, 1993.

Z. Lu, H. Pulpan, and M. Wyss, Geophysical Institute, University of Alaska, Fairbanks, AK 99775. (e-mail: lu@giseis.alaska.edu)

(Received February 5, 1996; revised October 28, 1996; accepted November 21, 1996.) 